\title{
Spatial analysis of Mount St. Helens tephra leachate compositions: implications for future sampling strategies
}

\author{
P. M. Ayris ${ }^{1}$ - P. Delmelle ${ }^{2}$ - B. Pereira ${ }^{2}$ - E. C. Maters $^{2}$ • D. E. Damby ${ }^{1}$. \\ A. J. Durant ${ }^{3,4}$ D. B. Dingwell ${ }^{1}$
}

Received: 10 December 2014 / Accepted: 5 June 2015 / Published online: 13 June 2015

(C) The Author(s) 2015. This article is published with open access at Springerlink.com

\begin{abstract}
Tephra particles in physically and chemically evolving volcanic plumes and clouds carry soluble sulphate and halide salts to the Earth's surface, ultimately depositing volcanogenic compounds into terrestrial or aquatic environments. Upon leaching of tephra in water, these salts dissolve rapidly. Previous studies have investigated the spatial and temporal variability of tephra leachate compositions during an eruption in order to gain insight into the mechanisms of gastephra interaction which emplace those salts. However, the leachate datasets analysed are typically small and may poorly represent the natural variability and complexity of tephra deposits. Here, we have conducted a retrospective analysis of published leachate analyses from the 18 May 1980 eruption of Mount St. Helens, Washington, analysing the spatial structure of the concentrations and relative abundances of soluble $\mathrm{Ca}, \mathrm{Cl}, \mathrm{Na}$ and $\mathrm{S}$ across the deposits. We have identified two spatial features: (1) concentrated tephra leachate compositions in blast deposits to the north of the volcano and (2) low S/Cl and $\mathrm{Na} / \mathrm{Cl}$ ratios around the Washington-Idaho border. By
\end{abstract}

Editorial responsibility: M.L. Coombs

P. M. Ayris

paul.ayris@min.uni-muenchen.de

1 Department of Earth and Environmental Sciences, Ludwig Maximilian University, Thereisenstrasse 41/III, 80333 Munich, Bavaria, Germany

2 Earth and Life Institute, Université Catholique de Louvain, Croix du Sud 2, bte L7.05.10, 1348 Louvain-la-Neuve, Wallonia, Belgium

3 Centre for Earth Evolution and Dynamics (CEED), University of Oslo, Blindern, Postbox 1028, 0315 Oslo, Norway

4 Geological and Mining Engineering and Sciences, Michigan Technological University, 1400 Townsend Drive, Houghton, MI 49931, USA reference to the bulk chemistry and granulometry of the deposit and to current knowledge of gas-tephra interactions, we suggest that the proximal enrichments are the product of preeruptive gas uptake during cryptodome emplacement. We speculate that the low $\mathrm{S} / \mathrm{Cl}$ and $\mathrm{Na} / \mathrm{Cl}$ ratios reflect a combination of compositional dependences on high-temperature $\mathrm{SO}_{2}$ uptake and preferential $\mathrm{HCl}$ uptake by hydrometeortephra aggregates, manifested in terrestrial deposits by tephra sedimentation and fallout patterns. However, despite our interrogation of the most exhaustive tephra leachate dataset available, it has become clear in this effort that more detailed insights into gas-tephra interaction mechanisms are prevented by the prevalent poor temporal and spatial representativeness of the collated data and the limited characterisation of the tephra deposits. Future leachate studies should aim to extensively sample across tephra deposit limits whilst simultaneously characterising deposit stratigraphy and tephra chemistry, mineralogy and granulometry, taking steps to ensure the quality and comparability of collected leachate datasets.

Keywords Mount St. Helens $\cdot$ Tephra $\cdot$ Leaching

\section{Introduction}

\section{Spatial analysis of tephra leachates}

Tephra releases significant quantities of soluble elements upon leaching in water. These are generally accepted to originate from the dissolution of soluble sulphate and halide salts on particle surfaces (Óskarsson 1980; Rose et al. 1973; Rose 1977; Taylor and Stoiber 1973). These salts derive from several types of interactions between volcanic gases and tephra particles. Within the eruption plume, salts may be physically deposited onto tephra particles upon rapid cooling of 
magmatic gases in the atmosphere (Taylor and Stoiber 1973) or formed via chemical reactions between gases and tephra surfaces (Ayris et al. 2013, 2014; Hoshyaripour et al. 2014; Óskarsson 1980). In the cold volcanic cloud, salts may form on tephra surfaces due to dissolution of tephra by volcanic acid aerosols (Delmelle et al. 2007; Rose 1977). Both the eruption plume and volcanic cloud environments are subject to rapid changes in temperature (Mastin 2007), eruptive gas chemistry and redox state (Hoshyaripour et al. 2012), chemistry, $\mathrm{pH}$ and number concentration of aerosols (Herzog et al. 1998; Textor et al. 2003). Thus, each tephra particle carries a unique assemblage of salts imparted by its individual trajectory through a physically and chemically evolving eruption plume and volcanic cloud.

Leachate analyses measure the mean soluble salt concentrations on all tephra particle surfaces in deposit subsamples. However, the tephra particles found within those subsamples, irrespective of location within the deposit, are emplaced as a result of processes which dictate sedimentation and deposition of tephra particles into terrestrial environments (e.g. wind and bulk tephra particle properties; Bonadonna and Phillips 2003). In other words, the leachate composition from a tephra deposit subsample is the partial product of processes which are independent of those governing gas-tephra interactions, and hence, the leachate compositions may be variably decoupled from gas-tephra interaction processes. This fact leads to the realisation that it may only be possible to reassemble the syn- and post-eruptive chemical history of any deposit subsample by investigation of the spatial variability of leachate compositions from many such subsamples across the tephra deposit.

Tephra leachate studies have been undertaken for a number of purposes, from seeking mechanistic insight into volcanic processes to investigations of the environmental or health impacts of tephra leaching in receiving environments (Witham et al. 2005 and references therein). A number of these previous studies have investigated the spatial variability of tephra leachate compositions; some have used these data to infer changes in eruption dynamics and magmatic gas composition (Stoiber et al. 1981), under the assumption that relative and total concentrations of $\mathrm{S}, \mathrm{Cl}$ and $\mathrm{F}$ in tephra leachates are a proxy for eruptive gas compositions, whereas others have analysed spatial trends in tephra leachate compositions to describe gastephra interaction processes in the eruption plume (Óskarsson 1980) or volcanic cloud (Bagnato et al. 2013; Rose 1977).

However, excluding the early work of Rose (1977), previous spatial studies (e.g. Armienta et al. 2002; Bagnato et al. 2013; Óskarsson 1980; Stoiber et al. 1981; Varekamp et al. 1984) have often relied on small datasets (i.e. 3-11 analyses). These may poorly represent the complex features of tephra deposits that may cover areas up to $10^{2}-10^{5} \mathrm{~km}^{2}$. Although some studies have reported datasets comprising up to 34 leachate analyses, these are composites of much smaller datasets from different phases of prolonged eruptions spread over days or weeks (e.g. Chaitén, Durant et al. 2012; Eyjafjallajökull, Bagnato et al. 2013). Such datasets can also be limited in their capacity to represent the deposits of individual eruptive phases, particularly when emplaced under variable environmental conditions. It has thus proven difficult to demonstrate spatial variability in tephra leachate compositions from these datasets and, consequently, to unambiguously relate that variability to volcanic and/or depositional factors.

Here we perform a retrospective evaluation of published leachate compositions from the 18 May 1980 eruption of Mount St. Helens (MSH), in Washington (WA), USA. The eruption datasets comprise more than 300 leachate analyses from 185 tephra samples, reported in ten different studies. Although, in our evaluation, differing leaching protocols render the majority of these incomparable (Table 1), the remaining comparable dataset still constitutes the largest for any single eruptive event in the published literature. Other tephra properties such as grain size distribution and bulk chemical composition have also been extensively documented (Fig. 1). The MSH eruption may thus represent the best opportunity for identifying and explaining any spatial variability in tephra leachate chemistry. We use statistical analyses to investigate spatial trends in total and relative abundances of soluble $\mathrm{S}, \mathrm{Cl}$, $\mathrm{Na}$ and $\mathrm{Ca}$ in tephra leachates. These trends are interpreted by reference to tephra deposit features and current understanding of gas-tephra interactions. Our analysis and interpretations emphasise the importance of extensive, rigorous sampling and in-depth characterisation of tephra deposits in leachate studies of future eruptions.

\section{MSH eruption overview}

The MSH eruption consisted of six distinct phases of activity over the first $24 \mathrm{~h}$ of the eruption (Criswell 1987; Waitt and Dzurisin 1981; Sarna-Wojcicki et al. 1981a; Carey et al. 1990; Pallister et al. 1992; see Table 1 in Durant et al. 2009 for a complete summary). The first phase began with the flank collapse landslide, the lateral blast resulting from the immediate depressurisation of the crystal-rich, dacitic cryptodome (Hoblitt et al. 1981) and subsequent co-ignimbrite plumes. The landslide and blast deposits were emplaced up to $12 \mathrm{~km}$ north of Mount St. Helens, between the volcano and the Mossyrock area in Washington (Fig. 1). Crystal-rich dacitic tephra from this initial phase was also deposited as fallout between MSH and Yakima, WA. The second phase featured a sustained Plinian column with a transition from the eruption of a dark-coloured dacitic tephra to a white, silica-rich dacitic pumice (Durant et al. 2009; Criswell 1987). Tephra was dispersed to the east of MSH; the dark-coloured tephra was deposited over Washington, only noted as a millimetre-thick basal layer at the WA-ID border by Sarna-Wojcicki et al. (1981a). The third and fourth phases of the eruption were dominated by smaller explosive events with pyroclastic flows and associated 
Table 1 List of papers (Fruchter et al. 1980; Hinkley et al. 1987; Jones and Gislason 2008; McKnight et al. 1981; Nehring and Johnston 1981; Smith et al. 1983; Sneva et al. 1982; Stoiber et al. 1981; Sung et al. 1982; Taylor and Lichte 1980) which report leachate compositions from the MSH eruption, detailing the number of samples collected (or collated) within the study; the number of leachate compositions reported by the study and the number of samples within that dataset which were extracted utilising only $\mathrm{H}_{2} \mathrm{O}$; the number of leachate compositions discarded and the remaining viable data collated in our initial survey of the available studies. Additional information regarding the rationale for data exclusion are indicated below the table

\begin{tabular}{|c|c|c|c|c|c|c|c|c|c|c|}
\hline \multirow[b]{2}{*}{ Year } & \multicolumn{10}{|c|}{ First author } \\
\hline & $\begin{array}{l}\text { Fruchter } \\
1980\end{array}$ & $\begin{array}{l}\text { Hinkley }{ }^{a, b} \\
1987\end{array}$ & $\begin{array}{l}\text { Jones }^{c} \\
2008\end{array}$ & $\begin{array}{l}\text { McKnight } \\
1981\end{array}$ & $\begin{array}{l}\text { Nehring }^{\mathrm{a}} \\
1981\end{array}$ & $\begin{array}{l}\text { Smith }^{\mathrm{b}} \\
1983\end{array}$ & $\begin{array}{l}\text { Sneva a, b, d } \\
1982\end{array}$ & $\begin{array}{l}\text { Stoiber } \\
1981\end{array}$ & $\begin{array}{l}\text { Sung } \\
1982\end{array}$ & $\begin{array}{l}\text { Taylor }^{\mathrm{e}} \\
1980\end{array}$ \\
\hline Ash samples & 9 & 69 & 1 & 1 & 13 & 19 & 33 & 21 & 3 & 16 \\
\hline Leachate compositions & 9 & 143 & 1 & $1^{\mathrm{a}}$ & 13 & 57 & 48 & 21 & 3 & 6 \\
\hline $\mathrm{H}_{2} \mathrm{O}$-leach & 9 & 68 & 1 & 0 & 13 & 14 & 19 & 21 & 3 & 6 \\
\hline Discarded compositions & 0 & 38 & 1 & 0 & 4 & 0 & 14 & 0 & 1 & 0 \\
\hline Viable compositions & 9 & 30 & 0 & 0 & 9 & 19 & 0 & 21 & 2 & 6 \\
\hline
\end{tabular}

${ }^{\text {a }}$ Study reports unpristine ash

${ }^{\mathrm{b}}$ Study reports values acquired from leaching experiments conducted in various leaching media

${ }^{\text {c }}$ Study reports leachate from a 28-year-old tephra sample, potentially influenced by 'leachate decay' (Jones and Gislason 2008)

${ }^{\mathrm{d}}$ Study reports mean values from an unpublished dataset

${ }^{\mathrm{e}}$ Study reports selection of values from an unpublished dataset

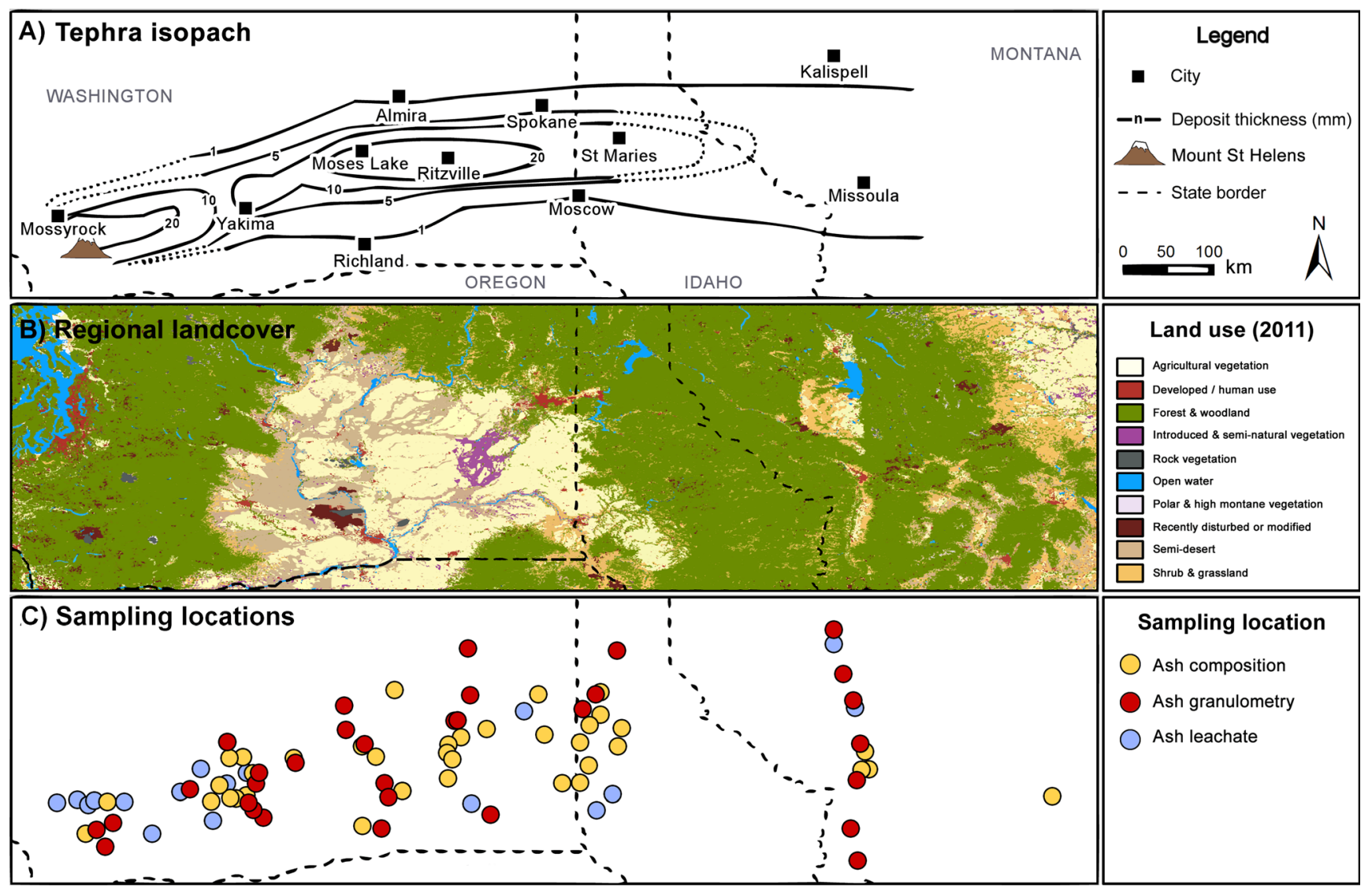

Fig. 1 Maps of a MSH 18 May 1980 deposit, including isolines of total deposit thickness $(\mathrm{mm})$ generated from data collated in Durant et al. (2009), and positions of state boundaries and cities named in the current study; b regional landcover for the year 2011, based on information from the 'National Gap Analysis Program Land Cover Data-Version 2'; and c positions of locations sampled for tephra composition analysis (yellowfilled circles), granulometry measurements (red-filled circles) and tephra leachate analysis (blue-filled circles). Although the regional landcover map is based on data from 2011, it is sufficient to illustrate the broad extent of geographic areas in our discussion 
co-ignimbrite column development (Durant et al. 2009). During these periods, fine-grained, glassy tephra was lofted into the atmosphere by co-ignimbrite plumes and dispersed over distal regions. The fifth and sixth phases of the eruption were dominated by small pyroclastic flows and weak tephra explosions (Criswell 1987). Changes in column height combined with vertical wind shear shifted the deposit axis approximately $40 \mathrm{~km}$ northwards throughout the period on activity on 18 May 1980 (Sarna-Wojcicki et al. 1981a). The distal (100 s km from source) tephra deposit featured a mass deposition maximum centred over Ritzville, WA, which formed from fallout of loosely bound tephra aggregates (Durant et al. 2009).

\section{Methods}

\section{Compiling a comparable leachate dataset}

\section{Comparability of different sampling and leaching methods}

The 302 tephra leachate compositions collated from ten previous studies (Table 1) were extracted and analysed by a variety of sampling and analytical techniques, impeding crosscomparison. In our analysis, we do not consider any tephra previously exposed to rainfall, as the pre-analysis dissolution of soluble salts prevents comparison with pristine tephra (c.f. Hinkley et al. 1987). We also exclude tephra samples recovered during the eruption; $60 \%$ of leachate compositions in Stoiber et al. (1981) and $9 \%$ from Hinkley et al. (1987) are from specific times during the eruption. As the vast majority of leachate compositions in the wider dataset were recovered after tephra deposition had abated, it is difficult to draw any comparison between a small number of time-specific samples, representing the leachate chemistry of a single moment or period of the eruption, to samples which represent that of the whole eruption. Hinkley et al. (1987) also included a number of analytical duplicates of the same tephra samples; to avoid artificially inflating the collated leachate dataset, we replace those data with a single calculated mean for each duplicate pair.

Across the ten studies, most tephra leachate compositions were obtained using deionised or distilled water as the leaching solution. For the sake of comparison, studies that used other extractants such as $\mathrm{H}_{2} \mathrm{SO}_{4}$ and $\mathrm{HNO}_{3}$ (Smith et al. 1983) were discarded from the dataset. Analysis of a range of tephra/water ratios (1.6:1 to 1:14) and leaching times ( 1 to $25 \mathrm{~h}$ ) was reported, further impeding comparison of data.

High tephra/water ratios can promote saturation of leaching solutions with respect to poorly and moderately water-soluble mineral phases, including gypsum $\left(\mathrm{CaSO}_{4} \cdot 2 \mathrm{H}_{2} \mathrm{O}\right.$, solubility product $\left.K_{\mathrm{Sp}}=2.4 \times 10^{-5}\right)$ and fluorite $\left(\mathrm{CaF}_{2}, K_{\mathrm{Sp}}=1.5 \times 10^{-10}\right.$; Barton 1991). Similarly, short leaching times may not achieve full dissolution of soluble salts. In both cases, leachate compositions may be unlikely to reliably reflect the soluble salt concentration on the tephra particle surfaces. In the case of the MSH leachate data, thermodynamic modelling and previous leaching studies (Taylor and Lichte 1980; Jones and Gislason 2008) imply that for $\mathrm{H}_{2} \mathrm{O}$-leached tephra samples, there may be no significant influence of tephra/water ratio or leaching time. Mineral saturation indices for MSH leachates calculated using PHREEQC predicts that, of the various chloride and sulphate salts which may exist on tephra surfaces, only $\mathrm{BaSO}_{4}$ was saturated in leachate solutions. As neither Hinkley et al. (1987) nor Smith et al. (1983) reported significant increases in $\mathrm{Ba}$ in more dilute and/or acidic leachates from MSH tephra, saturation effects have little impact on our collated dataset.

IVHHN guidelines (Stewart et al. 2013) consider that a leaching time of $1 \mathrm{~h}$ is sufficient to extract a representative quantity of soluble salts from tephra surfaces. However, leaching in this time may not achieve total dissolution of the soluble salt load. During three successive 4-h leaching experiments on MSH tephra, Taylor and Lichte (1980) reported that the initial leach extracted $75 \pm 20 \%$ of the total soluble $\mathrm{Ca}, \mathrm{Cl}$, $\mathrm{Na}$ and $\mathrm{S}$ release. Similarly, in continuous leaching of MSH tephra within a plug flow-through reactor over $8 \mathrm{~h}$, the data of Jones and Gislason (2008) show that an average of 54-68 $( \pm 18) \%$ of the total release of $\mathrm{Ca}, \mathrm{Cl}, \mathrm{Na}$ and $\mathrm{S}$ was mobilised within the first 50-100 min. The comparable extraction in these two time periods implies that there may only be a small difference in tephra leachate extracted after 1 and $4 \mathrm{~h}$ of immersion. However, the contrast between these samples and those leached for $25 \mathrm{~h}$ may be more significant. For the purposes of this study, we do not exclude samples on the basis of leaching time, but the effect of prolonged leaching on our interpretation of the collated data is considered in the section "Validity of observed spatial trends".

\section{Elements of interest}

The studies detailed in Table 1 collectively report concentrations for over 34 major, minor and trace elements in solution, with half of all analyses reporting non-zero concentrations of $\mathrm{Ba}, \mathrm{Ca}, \mathrm{Cl}, \mathrm{Cu}, \mathrm{Co}, \mathrm{F}, \mathrm{Fe}, \mathrm{Li}, \mathrm{Mg}, \mathrm{Mo}, \mathrm{Na}, \mathrm{S}, \mathrm{Si}, \mathrm{Sr}$, V and $\mathrm{Zn}$. In all samples, the dominant constituents of leachate solutions are $\mathrm{Ca}, \mathrm{Cl}, \mathrm{Na}$ and $\mathrm{S}$, and molar ratios of $\mathrm{Na} / \mathrm{Cl}$ and $\mathrm{Ca} / \mathrm{S}$ in MSH leachate solutions are approximately consistent with the 1:1 stoichiometric ratios expected from $\mathrm{NaCl}$ and $\mathrm{CaSO}_{4}$ dissolution (Fig. 2). Accordingly, we interpret trends in leachate compositions for MSH by reference to these four elements alone.

\section{Exclusion of outliers}

We analyse variations in soluble $\mathrm{Cl}, \mathrm{Ca}, \mathrm{Na}$ and $\mathrm{S}$ concentrations to identify and exclude outliers. The concentrations reported by Stoiber et al. (1981) are consistently higher than those of all other studies (Fig. 3), despite 
Fig. 2 Concentrations of a soluble $\mathrm{Ca}$ vs soluble $\mathrm{S}$ and $\mathbf{b}$ soluble $\mathrm{Na}$ vs soluble $\mathrm{Cl}$ extracted from studies that report data for all four elements; blue, Fruchter et al. (1980); yellow, Hinkley et al. 1987; pink, Nehring and Johnston (1981); green, Smith et al. (1983); orange, Taylor and Lichte (1980)

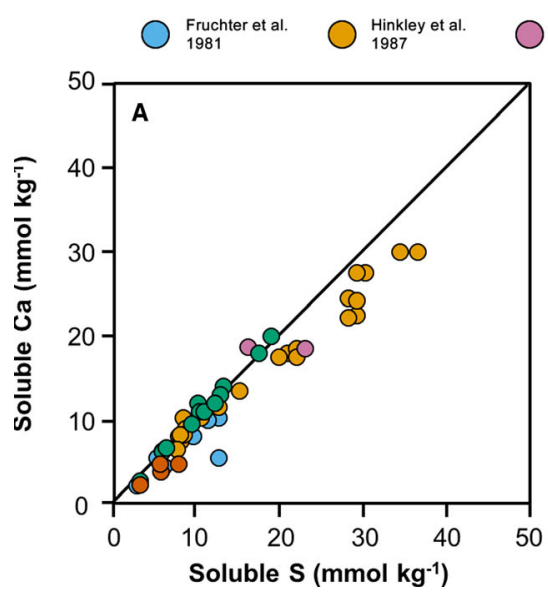

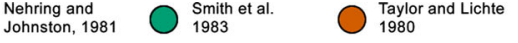

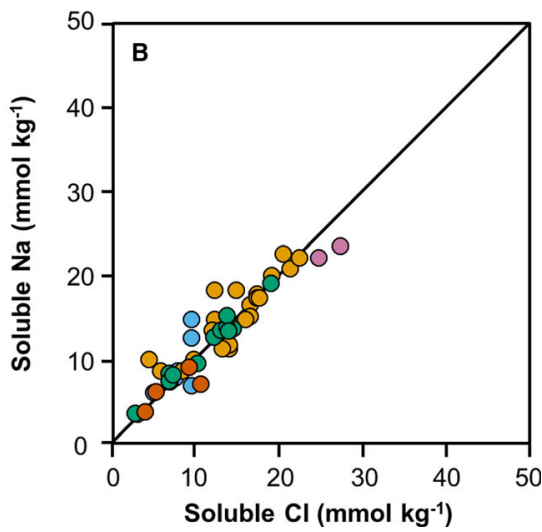

overlap in the spatial distribution of tephra samples. The dataset of Stoiber et al. (1981) may either be subject to systematic analytical error or differences in sampling practices which are not documented in the original study; in either case, we exclude that dataset from our study.

We analyse the variation in leachate concentrations at locations where duplicate data from one or more studies were collected. At each sampling site, it was assumed that each measured value should depend upon (i) a 'true' concentration value at that point and (ii) a random error following a normal distribution of 0 mean and $\sigma_{\mathrm{D}}$ standard deviation. The 'true' concentration value at the point is estimated by the mean of the field duplicate data, and the standard deviation of the random error is estimated by the pooled standard deviation (Nič et al. 2009). The assumption of a normal distribution in

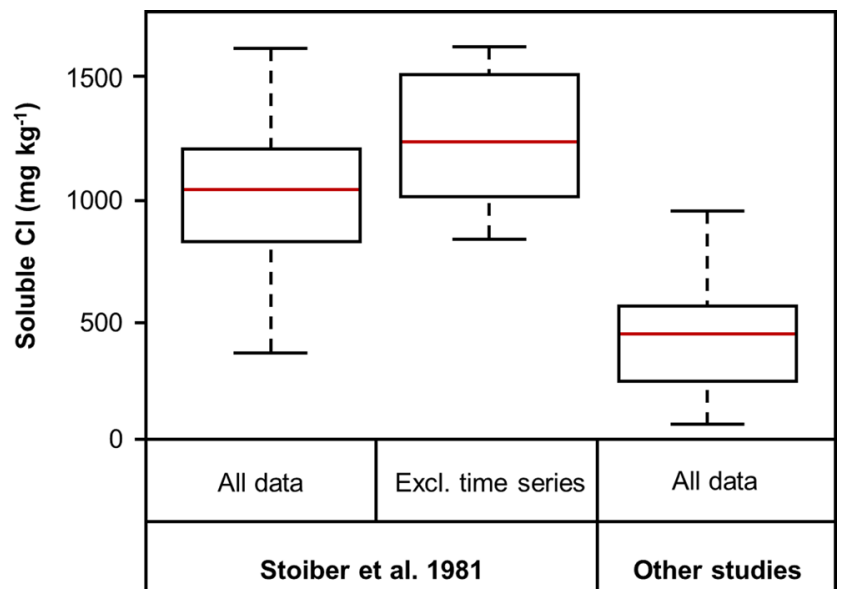

Fig. 3 Boxplot comparison of all 21 soluble $\mathrm{Cl}$ data $\left(\mathrm{mg} \mathrm{kg}^{-1}\right)$ from Stoiber et al. (1981), the subset of six soluble $\mathrm{Cl}$ that are not attributed to a specific sampling time (e.g. Almira, 1800 hours) or period (e.g. Spokane, 'early tephra fallout'), compared with all soluble $\mathrm{Cl}$ data from the five studies which also report $\mathrm{Cl}$ concentrations (Fruchter et al. 1980; Hinkley et al. 1987; Nehring and Johnston 1981; Smith et al. 1983; Taylor and Lichte 1980). The red line indicates the median of the respective datasets, whilst the extent of the white bar covers the interquartile ranges. The extent of the dashed lines indicates the maximum and minimum values of those datasets random error within the data has been verified by a ShapiroWilk test, where $\alpha=0.05$. Statistical outliers in duplicate data were considered to be those which fell outside of a $95 \%$ confidence interval calculated via Eq. (1).

$\overline{Y_{i}} \pm \sigma_{\mathrm{D}} * \mathrm{St}$

where $\bar{Y}_{i}$ is the mean value of the field duplicate data at point $i$, $\sigma_{\mathrm{D}}$ is the pooled standard deviation and $\mathrm{St}$ is the $1-\alpha / 2$ quantile of a t-distribution with the same degrees of freedom as the pooled standard deviation. We analysed $\mathrm{S}, \mathrm{Cl}, \mathrm{Ca}$ and $\mathrm{Na}$ and $\mathrm{S} / \mathrm{Cl}, \mathrm{Na} / \mathrm{Cl}$ and $\mathrm{Ca} / \mathrm{S}$ ratios following this treatment and excluded nine outliers from the collated elemental datasets: two from the soluble $\mathrm{Ca}$ dataset, two from soluble $\mathrm{Cl}$, two from soluble $\mathrm{Na}$ and three from soluble $\mathrm{S}$.

\section{Leachate composition summary}

The final collated MSH dataset utilised in our study comprises 56 leachate compositions from the MSH tephra deposit. This represents only $20 \%$ of the original 302 sample dataset, but nevertheless remains the largest for any single studied eruption. Tephra leachates are distributed across 32 locations across the deposit, although these locations are reported with varying precision. For example, Hinkley et al. (1987) report sampling locations using latitude and longitude, accurate to two decimal places $( \pm 1 \mathrm{~km})$, whilst Nehring and Johnston (1981) provided some locations utilising Public Land Survey System coordinates, introducing a maximum error of $\pm 2 \mathrm{~km}$. All other locations were reported with respect to a named city or landmark, sometimes combined with distance and bearing from that point (e.g. $20 \mathrm{~km} \mathrm{NW}$ of Spokane). Those locations are presumed to be situated at, or oriented with respect to, the geographic midpoint of the named areas. Approximating the land area of the named locations to circular envelopes, errors based on the envelope radius are 0.2 to $7 \mathrm{~km}$. For interpretation of broad-scale spatial features, there is little significance 
of these error envelopes; their areas are less than $0.5 \%$ of the whole deposit.

\section{Additional tephra characterisation data}

\section{Grain size dependence of leachate compositions}

As gas-tephra interaction mechanisms involve surficial reactions, leachate compositions should be normalised to the specific surface area (SSA, $\mathrm{m}^{2} \mathrm{~g}^{-1}$ ) of the tephra sample. No SSA analyses were undertaken in the collated studies; we therefore calculated geometric specific surface area $\left(\mathrm{SSA}_{\text {geo }}\right)$ values, calculated via Eq. (2) (Rumstidt 2013), where $p_{\mathrm{d}}$ is particle diameter $(\mathrm{m})$ and $\rho$ is individual particle density $\left(\mathrm{g} \mathrm{cm}^{-3}\right)$, from 37 particle size distributions taken from across the MSH deposit (Durant et al. 2009).

$\mathrm{SSA}_{\text {geo }}=\frac{6 \times 10^{-6}}{\rho p_{\mathrm{d}}}$

The particle size distributions of Durant et al. (2009) were measured using a Malvern Mastersizer 2000 laser diffraction analyser. We further analysed four more samples acquired for the current study using a Coulter Q-100 Laser Analyser and calculated their respective $\mathrm{SSA}_{\text {geo }}$ values. Both approaches assumed a particle refractive index of 1.6 and approximated particles to spheres with density of $2.5 \mathrm{~g} \mathrm{~cm}^{-3}$.

From this $\mathrm{SSA}_{\text {geo }}$ dataset, comprising 43 values in total, only three were located within the tephra fallout region west of Yakima, WA. Proximal deposits in this region are known to comprise material from multiple discrete events: the lateral blast, landslide and both co-ignimbrite and tephra fallout deposits (Waitt and Dzurisin 1981). As the complex, overlapping contributions of these disparate features cannot be represented by three samples alone, the three proximal $\mathrm{SSA}_{\text {geo }}$ values are excluded from our spatial analysis. The remaining $40 \mathrm{SSA}_{\text {geo }}$ values were situated on a deposit map according to their stated sampling location, considering any apparent spatial trends evident in that map to reflect changes in deposit granulometry.

A limitation of this treatment is that $\mathrm{SSA}_{\text {geo }}$ neglects the complex surface morphology of tephra particles, and so underestimates SSA (Ersoy et al. 2010). To determine whether such an impediment prevents interpretation of spatial trends in $\mathrm{SSA}_{\text {geo, }}$, we determined the SSA of 13 tephra samples from our dataset, calculated by application of the BrunauerEmmett-Teller (BET) theory (Brunauer et al. 1938) to measurements of $\mathrm{Kr}_{2}$ adsorption isotherms using a Micromeritics ASAP 2000 Surface Area Analyser. Figure 4 shows that for these samples, SSA measurements were approximately $3.5 \times$ higher than $\mathrm{SSA}_{\text {geo, }}$, but that the two were positively correlated with $r^{2}$ of 0.75 . This implies that for illustrative discussion of relative trends in tephra SSA across the whole tephra deposit,

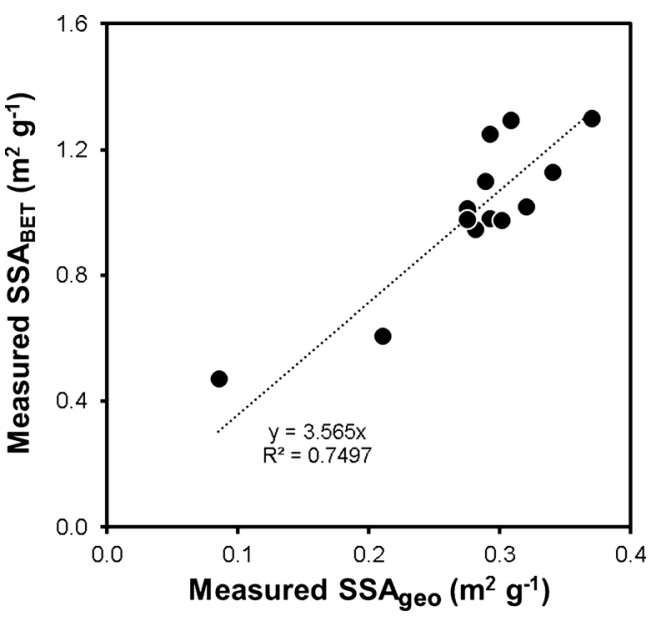

Fig. 4 Comparison of $\mathrm{SSA}_{\text {geo }}$ calculated from measured tephra particle size distributions and the $\mathrm{SSA}_{\mathrm{BET}}$ calculated from $\mathrm{K}_{2}$ adsorption isotherms for the same samples

the use of $\mathrm{SSA}_{\text {geo }}$ offers a reasonable approximation in this instance.

\section{Bulk chemical composition of tephra}

We collated 101 bulk chemical composition analyses for tephra samples recovered from 49 different locations from four different studies (Fruchter et al. 1980; Hinkley et al. 1987; Sarna-Wojcicki et al. 1981b; Smith et al. 1983). The locations from which these data were obtained were described with similarly variable precision as those sampled for leachate analysis. For all locations identified by name only, we assign a latitude and longitude according to the method described in the section "Compiling a comparable leachate dataset".

Hinkley et al. (1987) reported that for selected samples from across WA, ID and MT, leachate compositions showed significant correlation with bulk $\mathrm{Ca}, \mathrm{Na}$ and $\mathrm{Si}$ content. We therefore focus our analysis of deposit bulk chemical composition on these three elements, expressed as oxides (wt\%). We excluded four outliers: two for $\mathrm{CaO}$, one for $\mathrm{SiO}_{2}$ and one for $\mathrm{Na}_{2} \mathrm{O}$. The final collated dataset, averaging all replicate subsamples and excluding outliers, comprises 78 analyses. As multiple researchers often sampled in the same areas, these data were obtained from 44 discrete sampling locations.

\section{Data analysis}

To investigate spatial trends in MSH tephra leachates, we plot all compositional data (i.e. leachate and bulk tephra analyses) according to its geographic position. Where field duplicate data exists, we calculate and plot the mean concentration or value for that location. As no field duplicate data were available for $\mathrm{SSA}_{\text {geo }}$, each value obtained was assumed to be representative of the tephra deposit at that location. 
Based on the mean values for each location, we utilised the Geostatistical Analyst extension of the ArcGIS 10.1 software (ESRI 2012) to generate maps that illustrate any spatial structure in the distribution of leachate concentrations, tephra deposit bulk chemistry and granulometry across the deposit. These maps were generated by interpolation of data via ordinary kriging. Variograms were fitted using the 'nugget effect' and 'spherical model' structures.

\section{Results}

\section{Spatial analysis of raw data}

\section{Leachate compositions}

There are no clear spatial patterns in the maps of soluble $\mathrm{Ca}$, $\mathrm{Cl}, \mathrm{Na}$ and S (Fig. 5); high and low values are frequently encountered at the same location (e.g. Yakima, WA). However, two significant observations can be made. First, mean soluble $\mathrm{Ca}, \mathrm{Cl}, \mathrm{Na}$ and $\mathrm{S}$ concentrations are consistently high around $\mathrm{MSH}$. For $\mathrm{Cl}$ and S, 75 and $65 \%$, respectively, of values from the upper quartile range and $100 \%$ from the 90th percentile are found in this area (Fig. 5); for $\mathrm{Ca}$ and $\mathrm{Na}$, only two values, both in the 90th percentile, are located in the proximal region. Second, concentration values of all four elements are low at Yakima, WA and at Moses Lake, WA: at least $57 \%$ of mean soluble $\mathrm{Ca}, \mathrm{Cl}, \mathrm{Na}$ and $\mathrm{S}$ from the lowest quartile range and all below the 10th percentile. In addition to these two spatial features, higher concentrations of leachates can be identified in a single sampling location east of Missoula, MT, and another at Almira, WA; however, there is insufficient data in these regions to confirm any possible spatial trends.

\section{$S S A_{\text {geo }}$}

The SSA $_{\text {geo }}$ map (Fig. 6) shows a general trend of increasing $\mathrm{SSA}_{\text {geo }}$ from SW to NE across the tephra deposit. The lowest values are found in proximal regions; $90 \%$ of $\mathrm{SSA}_{\text {geo }}$ values below the 25th percentile are located west of Ritzville, WA, and over $90 \%$ of all $\mathrm{SSA}_{\text {geo }}$ values in that area are below the $33 \mathrm{rd}$ percentile. In contrast, $70 \%$ of $\mathrm{SSA}_{\text {geo }}$ values in the 75 th percentile are found beyond the WA-ID border, whilst only $25 \%$ of all $\mathrm{SSA}_{\text {geo }}$ values in that region fall below that range.

\section{Bulk chemical composition}

Maps of tephra deposit bulk $\mathrm{CaO}$ and $\mathrm{SiO}_{2}$ content are displayed in Fig. 7. The map of tephra deposit bulk $\mathrm{Na}_{2} \mathrm{O}$ content is excluded (see "Validity of observed spatial trends" section). All tephra deposits with mean $\mathrm{CaO}$ contents within the upper quartile range are located between Yakima, WA and Ritzville, WA, whilst those in the 90th percentile are situated around Yakima itself. All mean $\mathrm{CaO}$ contents in the lower quartile range are located in a region bordered by Ritzville and Spokane, WA, and St. Maries and Moscow, ID (hereafter, the 'RSSM' region). The reverse of this trend is observed in the $\mathrm{SiO}_{2}$ map; over $77 \%$ of locations reporting mean values within the lower quartile range are located between MSH and Yakima, WA, whilst over $90 \%$ from the upper quartile range are situated in the RSSM region.

\section{Spatial analysis of derived data}

\section{SSA-normalised leachate compositions}

Soluble salts are emplaced on tephra surfaces; therefore, normalisation of leachate compositions to tephra SSA may reveal different spatial trends and features to those identified in leachate concentrations when expressed per unit mass of tephra. In Fig. 8, we illustrate this effect by normalising the soluble $\mathrm{S}$ and $\mathrm{Cl}$ concentrations (Fig. 5) at each sampling location to the $\mathrm{SSA}_{\text {geo }}$ values at the same location predicted by kriging (Fig. 6). The proximity of most leachate sampling locations to those sampled for tephra granulometry measurements (Fig. 1) provides confidence in the validity of the predicted $\mathrm{SSA}_{\text {geo }}$ values. Maps of SSA-normalised $\mathrm{S}$ and $\mathrm{Cl}$ do not exhibit clear spatial patterns. The high and low values appear to be randomly distributed on the tephra deposition zone. The only spatial feature that could be inferred is a region of low SSAnormalised soluble $\mathrm{S}$ between Moses Lake, WA and St Maries, ID; all samples from the lower quartile range are located in this area, with $70 \%$ situated in the RSSM region, specifically. However, there is insufficient data, particularly between Moses Lake, WA and Ritzville, WA, to investigate this feature further.

Comparison between Figs. 5 and 8 demonstrates that normalising leachate compositions to $\mathrm{SSA}_{\text {geo }}$ can reveal alternative spatial trends to those identified from data expressed in concentration per unit mass of tephra; this is evidenced by the redistribution of the lowest concentrations of soluble $\mathrm{S}$ and $\mathrm{Cl}$ from the Yakima, WA area to more distal regions.

Although we attempt no interpretation of broad trends in $\mathrm{SSA}_{\text {geo }}$ data in proximal regions in Fig. 8, it is possible to place the leachate compositions of tephra recovered from Mossyrock and surrounding areas in context with the distal deposits by reference to stratigraphic records. Tephra within those areas predominantly featured high $\mathrm{S}$ and $\mathrm{Cl}$ concentrations per unit mass of tephra and were derived from finegrained $(\sim 63-125 \mu \mathrm{m})$ dacitic tephra deposited by the coignimbrite phase of the lateral blast (Hoblitt et al. 1981; Nehring and Johnston 1981). The $\mathrm{SSA}_{\text {geo }}$ of such fine- 


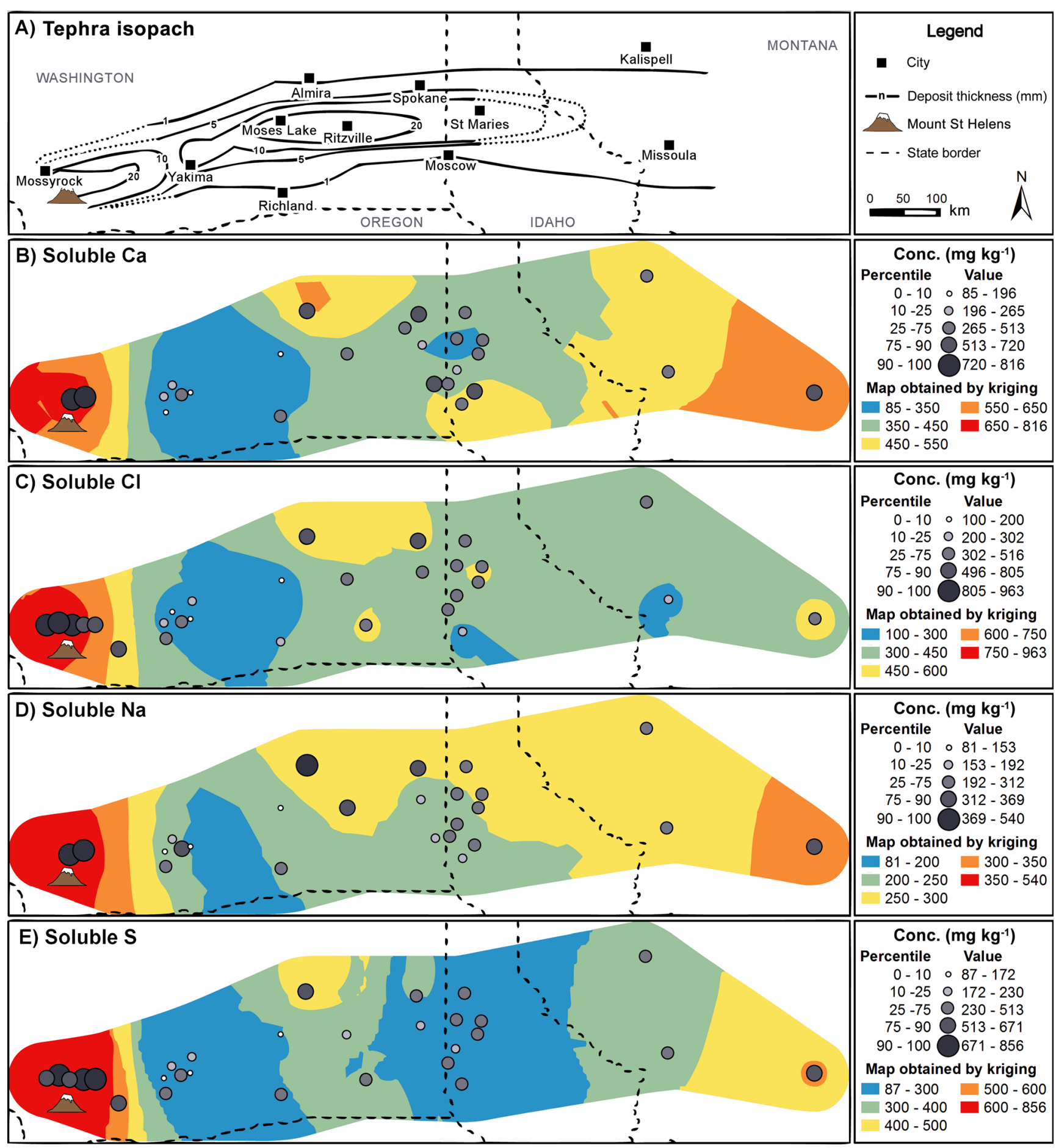

Fig. 5 Maps of a MSH tephra deposit isopachs and $\mathbf{b}$ mean soluble $\mathrm{Ca}, \mathbf{c} \mathrm{Cl}, \mathbf{d} \mathrm{Na}$ and $\mathbf{e} \mathrm{S}$, expressed in milligrams per kilogram in tephra leachates in this study

grained tephra deposits may thus be comparable to the distal deposits; thus, if the highest $\mathrm{SSA}_{\text {geo }}$ measured $\left(0.36 \mathrm{~m}^{2} \mathrm{~g}^{-1}\right)$ was assigned to leachate compositions from the Mossyrock area, all but one mean soluble $\mathrm{Cl}$ concentration, and two for mean soluble $\mathrm{S}$, would still fall in the 90th percentiles of their respective datasets. A lower assigned $\mathrm{SSA}_{\text {geo }}$ would further increase these values.

\section{Leachate elemental ratios}

The maps of soluble $\mathrm{S} / \mathrm{Cl}$ and $\mathrm{Na} / \mathrm{Cl}$ ratios are displayed in Fig. 9, whilst the map of $\mathrm{Ca} / \mathrm{S}$ is excluded (see "Validity of observed spatial trends" section). For $\mathrm{S} / \mathrm{Cl}$ and $\mathrm{Na} / \mathrm{Cl}$, all but one value within the lower quartile range are located in the RSSM 


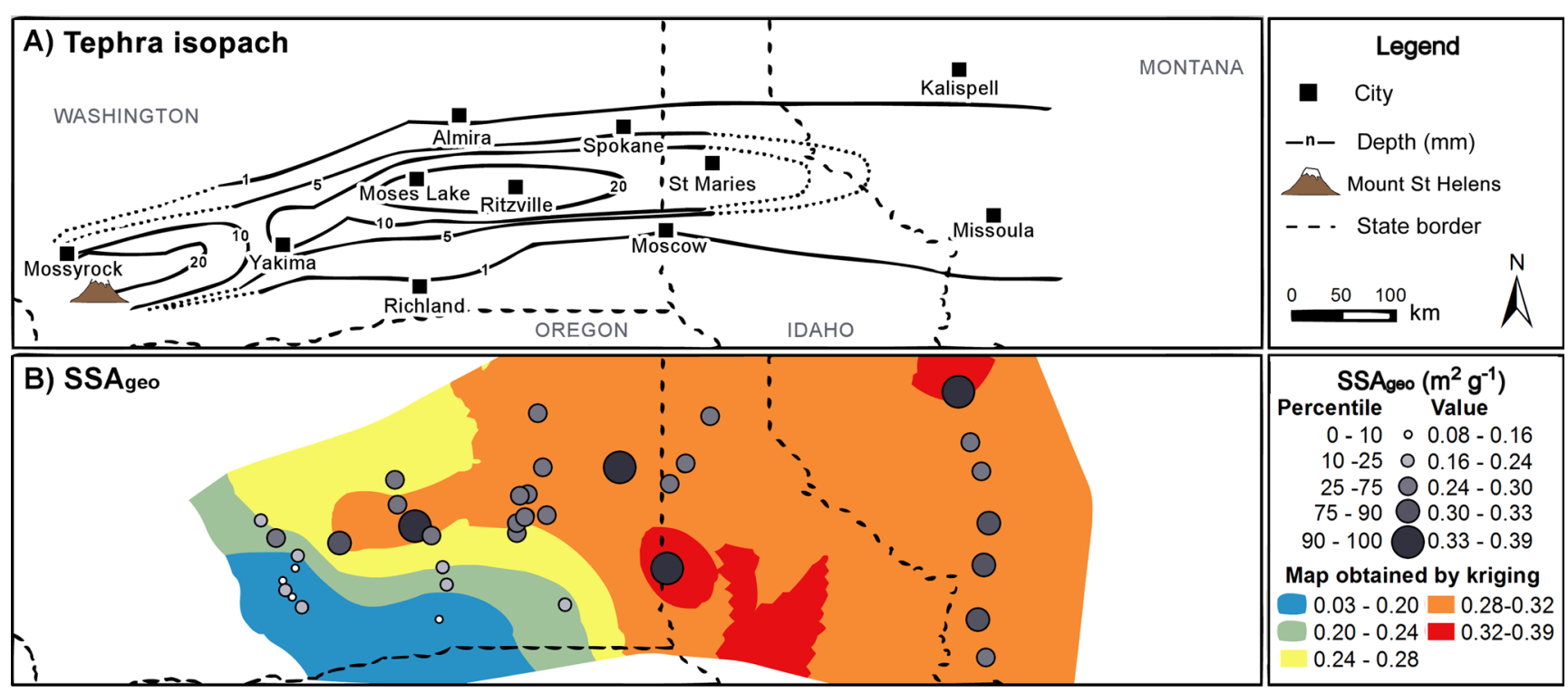

Fig. 6 Maps of a MSH tephra deposit isopachs and $\mathbf{b} \mathrm{SSA}_{\text {geo }}\left(\mathrm{m}^{2} \mathrm{~g}^{-1}\right)$ values. Black-filled circles in $\mathbf{b}$ indicate $\mathrm{SSA}_{\text {geo }}$ calculated from particle size distribution data from Durant et al. (2009) and the current study. The extent of the $\mathrm{SSA}_{\text {geo }}$ map is limited to areas east of Yakima, due to a lack of data in proximity to MSH

length of the distal deposits. Excluding the low $\mathrm{Na} /$ $\mathrm{Cl}$ and $\mathrm{S} / \mathrm{Cl}$ region, the maps exhibit no wider spatial trends.

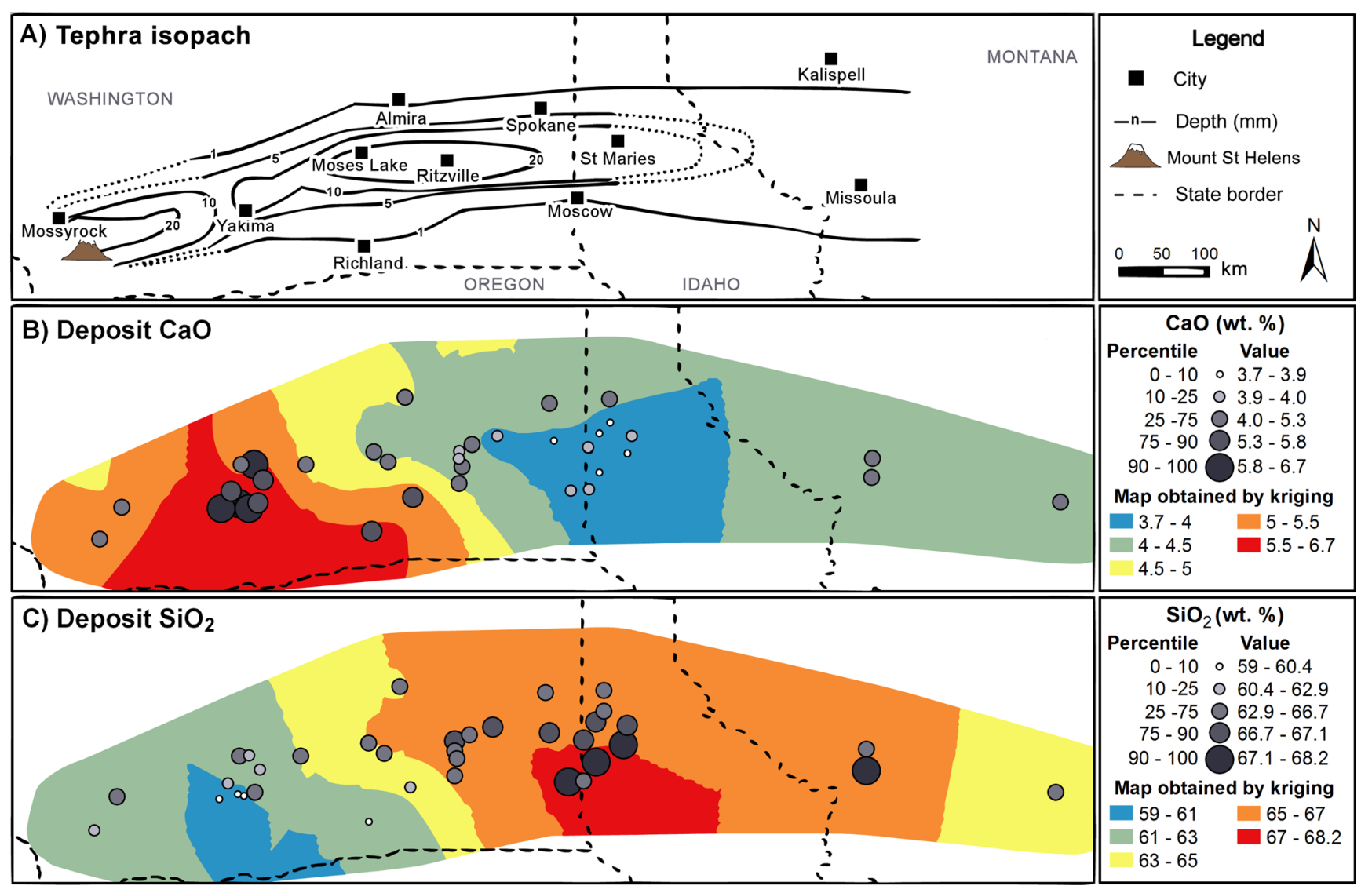

Fig. 7 Maps of a MSH tephra deposit isopachs and mean deposit b $\mathrm{CaO}$ and c) $\mathrm{SiO}_{2}$ content (wt\%) 


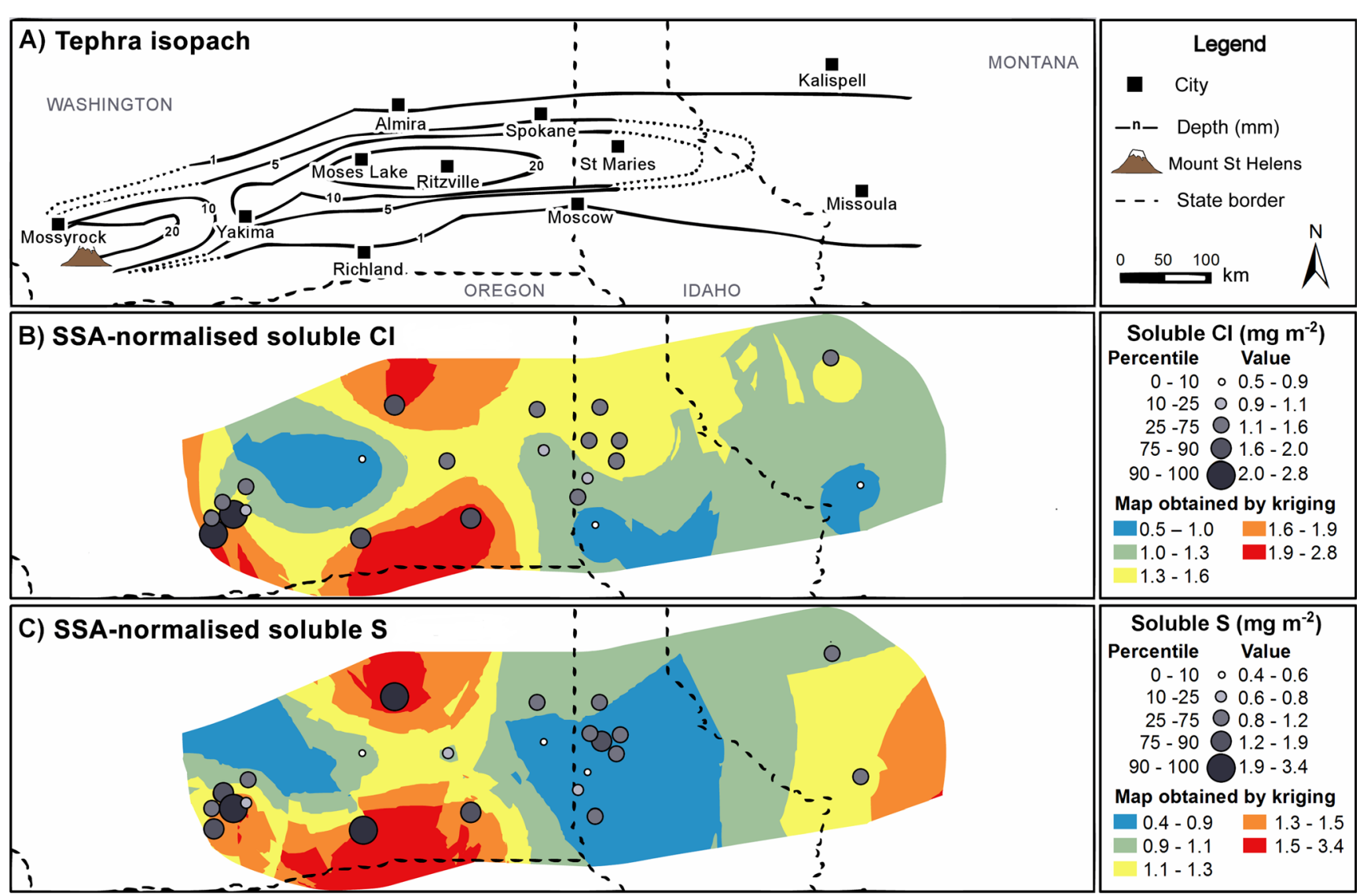

Fig. 8 Maps of a MSH tephra deposits and mean soluble $\mathbf{b} \mathrm{Cl}$ and $\mathbf{c} \mathrm{S}$ concentrations normalised to predicted $\mathrm{SSA}_{\text {geo }}$ values for each sampling location, based on Fig. 4. The underlying surface maps were produced by dividing the kriging results of $\mathrm{Cl}$ and $\mathrm{S}$ by the kriging result of $\mathrm{SSA}_{\text {geo }}$

\section{Validity of observed spatial trends}

\section{Local variability}

Mapping and interpretation of leachate and bulk chemical composition data is only appropriate if the variability of field duplicate data at individual sampling locations is less than the total variability of the dataset. If this is not the case, any inferred spatial trends could be ultimately the product of tephra sampling strategies that do not adequately represent local deposit variability, or of differences in leaching protocols. The statistical formula for pooled variance was used to calculate the variance of the field duplicate data for leachate and tephra bulk chemical composition data. Table 2 shows the relative contribution of field duplicate to total variance (\%) for all raw data, i.e. soluble $\mathrm{Ca}, \mathrm{Cl}, \mathrm{Na}$ and $\mathrm{S}$ and bulk tephra $\mathrm{CaO}, \mathrm{Na}_{2} \mathrm{O}$ and $\mathrm{SiO}_{2}$ content, and for derived data, i.e. soluble $\mathrm{Ca} / \mathrm{S}, \mathrm{Na} /$ $\mathrm{Cl}$ and $\mathrm{S} / \mathrm{Cl}$ ratios. We assume that if field duplicate variance is greater than $50 \%$ of the total variance of the whole dataset, mapping of data, and accordingly, interpretation of any spatial features, is not justified. The contribution of field duplicate variance for all datasets is less than $50 \%$, with the exception of $\mathrm{Na}_{2} \mathrm{O}(71 \%)$ and $\mathrm{Ca} / \mathrm{S}(64 \%)$; hence, the latter two datasets were excluded in our analysis.

\section{Influence of variable leaching times}

Tephra samples leached for $25 \mathrm{~h}$ may release proportionally more soluble $\mathrm{Ca}, \mathrm{Cl}, \mathrm{Na}$ and $\mathrm{S}$ than those leached for $4 \mathrm{~h}$ or fewer. This is demonstrated at eight locations within the collated dataset, which contain leachate compositions derived from one or more tephra samples which were leached for (i) a period of between 1 and $4 \mathrm{~h}$ (i.e. Fruchter et al. 1980; Hinkley et al. 1987, Nehring and Johnston 1981) and (ii) $25 \mathrm{~h}$ (Smith et al. 1983). At each location, we calculated the mean soluble $\mathrm{Ca}, \mathrm{Cl}, \mathrm{Na}$ and $\mathrm{S}$ concentrations for, and thus the mean relative difference between, leachate compositions from the two time periods. Figure 10 shows that across all four elements at the eight locations, the median ratio of $1-4: 25 \mathrm{~h}$ data is 0.80 , and all values within the interquartile range are less than unity. However, Fig. 10 also shows that there is only a weak dependence on leaching time for mean $\mathrm{S} / \mathrm{Cl}$ ratios, although only four of the eight locations provide data for these calculations. These data suggest that whilst $\mathrm{S} / \mathrm{Cl}$ ratios are unaffected, short duration leaching experiments underestimate the true concentrations of elements in solution. As the majority of leachate compositions in our analysis are derived from 1 to $4 \mathrm{~h}$ leaching experiments, we instead consider that soluble $\mathrm{Ca}, \mathrm{Cl}, \mathrm{S}$ and $\mathrm{Na}$ concentrations are consistently 


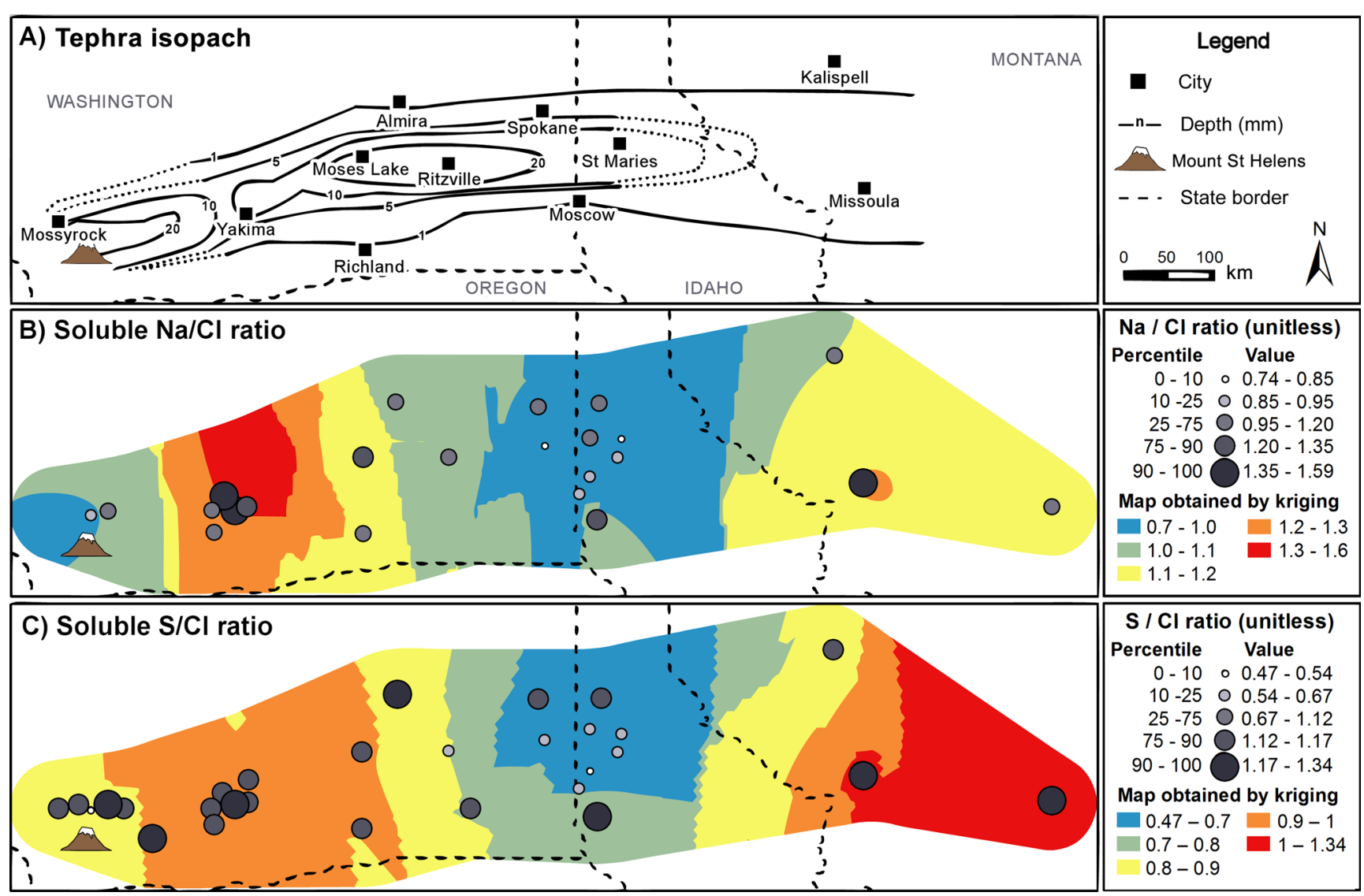

Fig. 9 Maps of a MSH tephra deposits and $\mathbf{b}$ mean soluble $\mathrm{Na} / \mathrm{Cl}$ and $\mathbf{c} \mathrm{S} / \mathrm{Cl}$ ratios in solution, based on the data from Fig. $5 \mathrm{c}-\mathrm{e}$

overestimated in locations where tephra samples were leached for $25 \mathrm{~h}$.

\section{Discussion}

Syn- and post-eruptive origins of leachate spatial features

We identified two distinct deposit features: (i) high mean soluble $\mathrm{Ca}, \mathrm{Cl}, \mathrm{Na}$ and $\mathrm{S}$ concentrations per unit mass (Fig. 5) and per unit tephra particle surface area (Fig. 8), in finegrained samples from blast zone deposits to the north of the volcano, and (ii) a region of low $\mathrm{S} / \mathrm{Cl}, \mathrm{Na} / \mathrm{Cl}$ and SSAnormalised soluble $\mathrm{S}$ concentrations in the RSSM region (Fig. 9). The effect of leaching time does not compromise the validity of these spatial features; only one location of five in the proximal region includes data from $25 \mathrm{~h}$ leaching experiments, and the exclusion of $25 \mathrm{~h}$ data in the distal field only serves to magnify the disparity between the two regions. Similarly, the variation in $\mathrm{S} / \mathrm{Cl}$ ratios observed is slight and cannot account for the observed discrepancy between low $\mathrm{S} / \mathrm{Cl}$ ratios in the RSSM region and higher values in the surrounding area. We therefore interpret these identified spatial features by reference to our current understanding of gastephra interactions.

\section{Proximal enrichments in soluble $\mathrm{S}$ and $\mathrm{Cl}$}

The proximal enrichments in soluble $\mathrm{S}$ and $\mathrm{Cl}$ were previously noted by Stoiber et al. (1981) who suggested that this was indicative of interactions with a 'large magmatic gas component in the directed blast and early in the eruption which decreased with time'. This gas component was considered to be $\mathrm{SO}_{2}$-rich and $\mathrm{HCl}$-poor, in contrast to that erupted in the later stages of the eruption. However, the proximal enrichments in soluble $\mathrm{S}$ and $\mathrm{Cl}$ can also be attributed to a prolonged period of pre-eruptive gas-rock interactions within the cryptodome. Rock samples taken from the dome formed at MSH in 2004 showed extensive cubic and bleb-like surface deposits on internal surfaces (Fig. 11), morphologically identical to $\mathrm{CaSO}_{4}$ and $\mathrm{NaCl}$ deposits formed by high-temperature adsorption on volcanic glass surfaces (Ayris et al. 2013, 2014). Similar deposits were observed on internal surfaces of blast zone deposits from the MSH eruption (Fig. 11). As the cryptodome was emplaced over a period of several weeks (Cashman 1992), the timescale of pre-eruptive gas adsorption may be up to five orders of magnitude longer than during the eruption itself (e.g. Mastin 2007). Crucially, this model can account for the observed leachate feature without necessitating a change in magmatic gas composition during the eruption. 
Table 2 Pooled variance of collated datasets (Tv), all field duplicate data $(\mathrm{Fv})$ within those datasets and the relative contribution of $\mathrm{Fv}$ to $\mathrm{Tv}(\%)$, for soluble $\mathrm{Ca}, \mathrm{Cl}, \mathrm{Na}$ and $\mathrm{S}$; ratios of soluble $\mathrm{Ca} / \mathrm{S}, \mathrm{Na} / \mathrm{Cl}$ and $\mathrm{S} / \mathrm{Cl}$; and bulk tephra $\mathrm{CaO}, \mathrm{Na}_{2} \mathrm{O}$ and $\mathrm{SiO}_{2}$ content

\begin{tabular}{llll}
\hline Dataset & Total variance (Tv) & Field duplicate variance $(\mathrm{Fv})$ & Fv/Tv (\%) \\
\hline $\begin{array}{l}\text { Leachate } \\
\text { Total conc. }\left(\mathrm{mg} \mathrm{kg}^{-1}\right)\end{array}$ & & \\
$\quad \mathrm{Ca}$ & 45,000 & 9530 & 21 \\
$\mathrm{Cl}$ & 45,200 & 14,400 & 32 \\
$\mathrm{Na}$ & 12,100 & 2990 & 25 \\
$\mathrm{~S}$ & 42,900 & 7960 & 19 \\
$\mathrm{Ratio}($ unitless $)$ & & & 64 \\
$\mathrm{Ca} / \mathrm{S}$ & 0.0217 & 0.014 & 38 \\
$\mathrm{Na} / \mathrm{Cl}$ & 0.0317 & 0.012 & 38 \\
$\mathrm{~S} / \mathrm{Cl}$ & 0.0654 & 0.0246 & \\
$\mathrm{Bulk}$ ash & & & 25 \\
$\mathrm{Composition}($ wt $\%)$ & & & 71 \\
$\mathrm{CaO}$ & 0.636 & 0.162 & 36 \\
$\mathrm{Na}{ }_{2} \mathrm{O}$ & 0.0326 & 0.0233 & \\
$\mathrm{SiO}$ & 6.28 & 2.29 & \\
\hline
\end{tabular}

\section{Distal depletions in elemental ratios and SSA-normalised S}

The lowest $\mathrm{S} / \mathrm{Cl}, \mathrm{Na} / \mathrm{Cl}$ and SSA-normalised soluble $\mathrm{S}$ concentrations in tephra leachates are identified in the RSSM

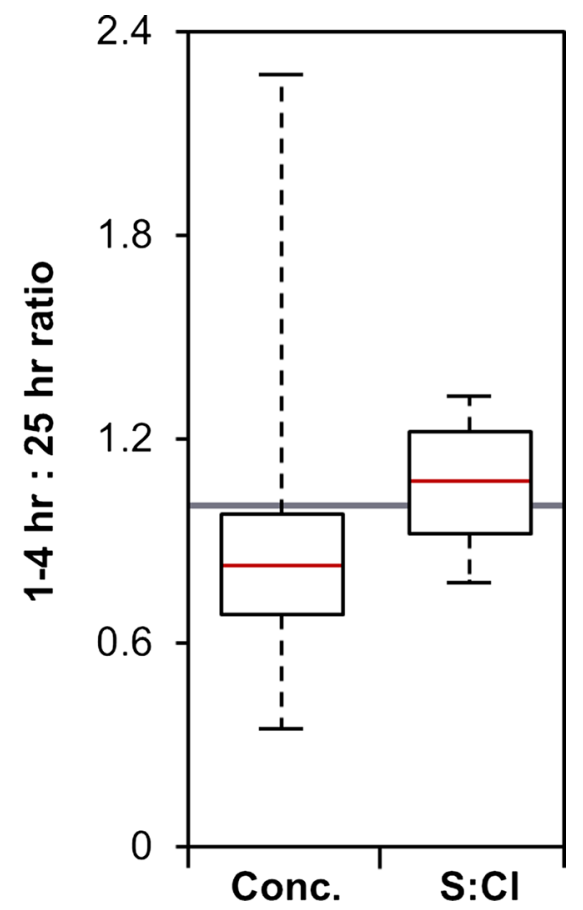

Fig. 10 Boxplot comparison of ratios of (i) total soluble $\mathrm{Ca}, \mathrm{Cl}, \mathrm{S}$ and $\mathrm{Na}$ in $1-4 \mathrm{~h}$ relative to $25 \mathrm{~h}$ leaching experiments at eight locations across the MSH tephra deposit and (ii) soluble $\mathrm{S} / \mathrm{Cl}$ ratios in $1-4 \mathrm{~h}$ relative to $25 \mathrm{~h}$ leaching experiments at four locations across the MSH tephra deposit. The red line indicates the median of the respective datasets, whilst the extent of the white bar covers the interquartile ranges. The extent of the dashed lines indicates the maximum and minimum values of those datasets region, although the validity of the region of low SSAnormalised soluble $\mathrm{S}$, which may have its onset as far west as Moses Lake, WA, is uncertain. These features coincide with increasingly Si-rich, Ca-poor tephra deposits (Fig. 7b, c), with an apparent locus in the RSSM area. They also coincide with the distal maximum in the deposit mass accumulation, where the heaviest deposition of weakly bound tephra cluster aggregates occurred (Durant et al. 2009; Sorem 1982).

Compositional dependences on leachate chemistry across the tephra deposit have been noted by Hinkley et al. (1987); soluble $\mathrm{S}$ and $\mathrm{Ca}$ were found to be positively correlated with tephra deposit $\mathrm{CaO}$ content and negatively correlated with tephra deposit $\mathrm{SiO}_{2}$ content. Such correlations may be indicative of high-temperature adsorption of $\mathrm{SO}_{2}$ by tephra surfaces in the first seconds after tephra emission (Ayris et al. 2013, 2014). In short duration experiments on silicate glasses, Ayris et al. (2013) observed that high-temperature $\mathrm{SO}_{2}$ adsorption, forming $\mathrm{CaSO}_{4}$, increased with glass $\mathrm{Ca}$ content. That study assumed crystal phases to be unreactive to $\mathrm{SO}_{2}$, but Henley et al. (2015) stated that, albeit over longer timescales, crystalline and amorphous anorthite $\left(\mathrm{CaAl}_{2} \mathrm{Si}_{2} \mathrm{O}_{8}\right)$ exhibited comparable reactivity with $\mathrm{SO}_{2}$. Under the assumption of the same comparable reactivity, high-temperature $\mathrm{SO}_{2}$ uptake, and accordingly $\mathrm{CaSO}_{4}$ formation, may be broadly correlated with bulk tephra $\mathrm{CaO}$ content, irrespective of mineralogy.

The potential for $\mathrm{HCl}$ adsorption within the hot eruption plume may be significantly less than that of $\mathrm{SO}_{2}$. Ayris et al. (2014) observed that high-temperature adsorption of $\mathrm{HCl}$ was negligible in dacite and rhyolite glasses, attributing this to limited reactivity of $\mathrm{Na}^{+}$coordinated with tetrahedral $\left[\mathrm{AlO}_{4}\right]^{-}$and $\left[\mathrm{FeO}_{4}\right]^{-}$groups within those materials. Limited high-temperature adsorption may instead imply that $\mathrm{HCl}$ 
Fig. 11 SEM images of a internal surface of MSH dome rock sampled directly by CVO helicopter in May 2004; b internal surface of 1980 cryptodome dacite boulder, recovered from Toutle River, WA in 2009; and c dacite glass surfaces coated with cubic $\mathrm{CaSO}_{4}$ deposits formed after exposure to $1 \% \mathrm{SO}_{2}$ in air at $800{ }^{\circ} \mathrm{C}$ for $3600 \mathrm{~s}$ (Ayris et al. 2013). Cubic and rectangular deposits, ranging from hundreds of nanometres to micrometres in size, are strongly indicative of the presence of soluble surface salts on these samples
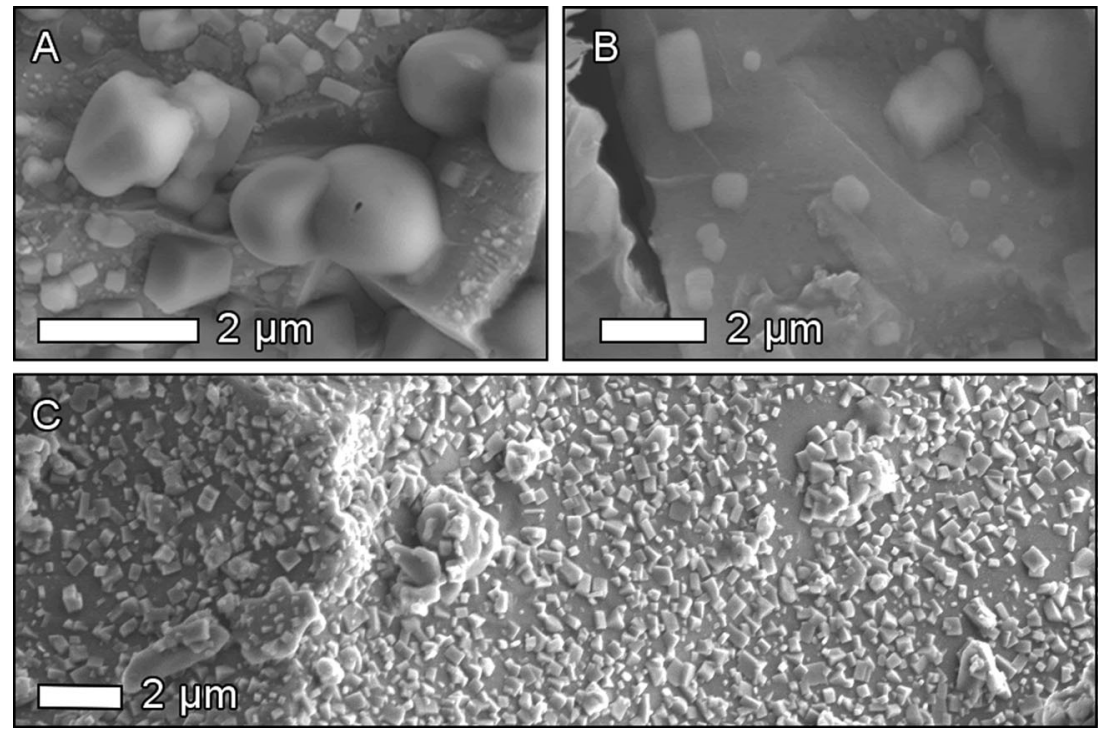

uptake is dominated by scavenging mechanisms acting in the cold volcanic cloud. Based on numerical simulations using the Active Tracer High Resolution Atmospheric Model (ATHAM), Textor et al. (2003) predicted that the high solubility of $\mathrm{HCl}$ would result in its rapid dissolution into liquid water and ice, whether as individual hydrometeors or as coatings on tephra surfaces (hydrometeor-tephra aggregates). In their simulations of a large stratospheric eruption, approximately half of all erupted $\mathrm{HCl}$ was sequestered into hydrometeors and hydrometeor-tephra aggregates within $60 \mathrm{~min}$ of the eruption onset. In contrast, virtually all $\mathrm{SO}_{2}$, being poorly soluble in either water or ice, remained within the volcanic cloud. As Sarna-Wojcicki et al. (1981a) report that within $1 \mathrm{~h}$ of the start of the eruption, tephra deposition was confined to areas west of Yakima, it would be expected that hydrometeortephra aggregate scavenging of $\mathrm{HCl}$ would be a predominantly proximal phenomenon.

In combination with tephra dispersal, aggregation and sedimentation processes, the $\mathrm{SO}_{2}$ and $\mathrm{HCl}$ uptake models proposed can explain the observed spatial features within $\mathrm{MSH}$ leachate data. In the high-temperature eruption plume, $\mathrm{SO}_{2}$ would be most efficiently scavenged by the most Ca-rich particles; at MSH, these were dense crystal-rich tephra, more extensively produced during the early eruption of highly evolved cryptodome material than in the later eruption of juvenile magma (Sarna-Wojcicki et al. 1981a; Scheidegger et al. 1982). In either case, these tephra were preferentially deposited in proximal regions. In contrast, Ca-poor silicic tephra with limited reactivity to $\mathrm{SO}_{2}$ was deposited in the RSSM region. If $\mathrm{HCl}$ scavenging occurs in proximal regions and is thus dictated by solubility in water and ice coatings on tephra surfaces, then there should be no spatial trend, other than a dependence on tephra SSA, and hence at least partially on granulometry, in soluble $\mathrm{Cl}$ concentrations across the tephra deposit. In this scenario, $\mathrm{S} / \mathrm{Cl}$ ratios across the deposit would be driven by the variable reactivity of tephra to $\mathrm{SO}_{2}$, mediated by temporal changes within the eruption and by tephra sedimentation patterns. Such an uptake-dependent model explains the low SSA-normalised soluble $\mathrm{S}$ and $\mathrm{S} / \mathrm{Cl}$ regions noted here and also offers an alternative explanation for the varying $\mathrm{S} / \mathrm{Cl}$ ratios in 'early' and 'late' tephra noted by Stoiber et al. (1981).

The abundance of Ca-poor tephra in the RSSM region, and hence the particular spatial location of low $\mathrm{S} / \mathrm{Cl}$ ratios, can be attributed to the formation and fallout of tephra aggregates. Durant et al. (2009) proposed that observations of weakly turbulent mammatus lobes at the base of the volcanic cloud over a wide area (including Ephrata, WA; Moses Lake, WA; and Vantage, WA) implicated bulk settling of the cloud layer driven by ice crystal formation and sublimation at the cloud base. Preferential aggregation of ice-laden, and hence $\mathrm{Cl}$-rich, ultra-fine tephra $\left(p_{\mathrm{d}} 8-31 \mu \mathrm{m}\right)$, principally comprised of silicic pumice and glass shards (Carey and Sigurdsson 1982), occurred in this region. Subsequent passage through the $0{ }^{\circ} \mathrm{C}$ isotherm caused ice to melt and form a liquid phase, which increased the rate of particle aggregation (Durant et al. 2009). Although Textor et al. (2003) predicted that $\mathrm{HCl}$ would be degassed during ice melting and/or sublimation, their models exclude the chemical interaction of $\mathrm{HCl}$ with the tephra surface. It may be possible that both prior to freezing and after thawing, acidic liquid films leach alkali and alkaline-earth cations from tephra surfaces. However, in the RSSM region, the limited capacity for leaching of $\mathrm{Na}^{+}$by $\mathrm{HCl}$ in highly silicic glass shards (Ayris et al. 2014) may promote the additional leaching of other cations. These would be ultimately deposited as assorted chloride salts on tephra aggregate surfaces during evaporation of the newly thawed liquid film, resulting in a low $\mathrm{Na} / \mathrm{Cl}$ ratio in leachate compositions, as is evident in Fig. 9. 


\section{Implications for leachate analysis}

\section{Standardised analytical techniques}

The 2013 IVHHN working group report 'Protocol for analysis of volcanic ash samples for assessment of hazards from leachable elements' (Stewart et al. 2013) offers a revised protocol of recommended practices for sample collection, storage, preparation and leaching, to promote acquisition of high-quality leachate compositions which can be more easily compared to that of other studies. Our analysis illustrates the utility of such protocols, as their use would have precluded any assumptions regarding leachate composition comparability. However, we emphasise that standardised leachate protocols do not guarantee a dataset free from analytical artefacts, and thus, should be complemented by secondary supporting analyses. In our interrogation of the MSH data, we noted that the short leaching times used in some studies, comparable to those recommended in the IVHHN guidelines, only achieved partial dissolution of soluble salts. Confidence in the representativeness of these leachates was only acquired via comparison with data derived from longer duration leaching experiments (e.g. Taylor and Lichte 1980; Smith et al. 1983; Jones and Gislason 2008). Our analysis also highlighted the possibility of systematic analytical error in the data of Stoiber et al. (1981), whereby soluble S and Cl concentrations were consistently higher than those of other studies at the same location. As systematic analytical error is difficult to detect, future leachate studies would benefit from a universal reference material, i.e. a wellcharacterised tephra sample with known leachate composition, verified by independent laboratories, or a synthetic tephra material which can be consistently reproduced in large quantities.

\section{Spatial and temporal variability}

The spatial features identified in our analysis demonstrate that small leachate datasets from large tephra deposits can fail to represent the complexities of the wider deposit. Whilst Stoiber et al. (1981) examined seven samples from Yakima, Spokane and Missoula and noted that $\mathrm{S} / \mathrm{Cl}$ ratios increased with increasing distance from the volcano, our analysis identified a region of low S/Cl ratios near Spokane, east of the WA-ID border. Thus, the inferred trend of Stoiber et al. (1981) is an artefact of undersampling. However, even our collated dataset is subject to sampling density limitations; the deposit margins and most distal deposits were poorly sampled, notably in the heavily forested regions of northern Idaho (Fig. 1). This undersampling may mask unidentified spatial trends, or alter the extent, and hence interpretation, of those already identified. A more extensive leachate dataset with a homogeneous distribution of samples across the deposit would have better resolved the observed, or additional, spatial features.

Additionally, although the uptake-dependent model proposed in the section "Syn- and post-eruptive origins of leachate spatial features" offers an explanation for features noted in time-series leachate compositions (e.g. Stoiber et al. 1981; Hinkley et al. 1987), we note that such data are scarce. It is possible that with a greater quantity of similar time-series leaching, if coupled with sampling of other deposit properties (i.e. chemical composition, mineralogy) that further evidence in support of, or perhaps contrary to, the proposed model, could have been obtained. However, it is crucial to emphasise that in a time-dependent analysis, leachate datasets must still be (a) spatially representative and (b) coupled with detailed analysis of deposit stratigraphy and tephra physical and chemical properties.

In any spatio-temporal interrogation of leachate data, it is vital to consider the influence of local-scale intradeposit variability. Field duplicate variability of total soluble $\mathrm{Ca}, \mathrm{Cl}, \mathrm{S}$ and $\mathrm{Na}$ concentrations per unit mass of tephra was low and may be most strongly influenced by varying SSA and the influence of different leaching times. However, the large variability of $\mathrm{S} / \mathrm{Cl}$ and $\mathrm{Na} / \mathrm{Cl}$ ratios (38\%, Table 2), presumed to be independent of these variables, may therefore be indicative of natural deposit variation. This possibility highlights the risk that single tephra samples may poorly represent local deposit variability in leachate compositions, requiring more extensive sampling of each location. In the current study, such data could have validated samples previously considered to be outliers, or identified additional data as anomalous. Current IVHHN guidelines recommend acquiring and compositing multiple samples from an area where deposits appear heterogeneous. For any spatial analysis of leachate compositions, greater sampling may be necessary in all cases, as there is no visible indicator of leachate heterogeneity. Similarly, whilst appropriate for impact assessment, pre-analysis compositing of samples to create a 'blind' mean would be undesirable for spatio-temporal or mechanistic interrogations, as it prevents any measure of local-scale variability. This could lead to over-interpretation of small variations in leachate compositions and the conflation of local and regional-scale variability.

\section{Pristine tephra}

It is well established that soluble salts can be dissolved by rainfall, and we accordingly excluded 49 leachate compositions from our analysis. However, the extent to which leachate compositions can be compromised by rainfall bears emphasis. At MSH, Hinkley et al. (1987) 


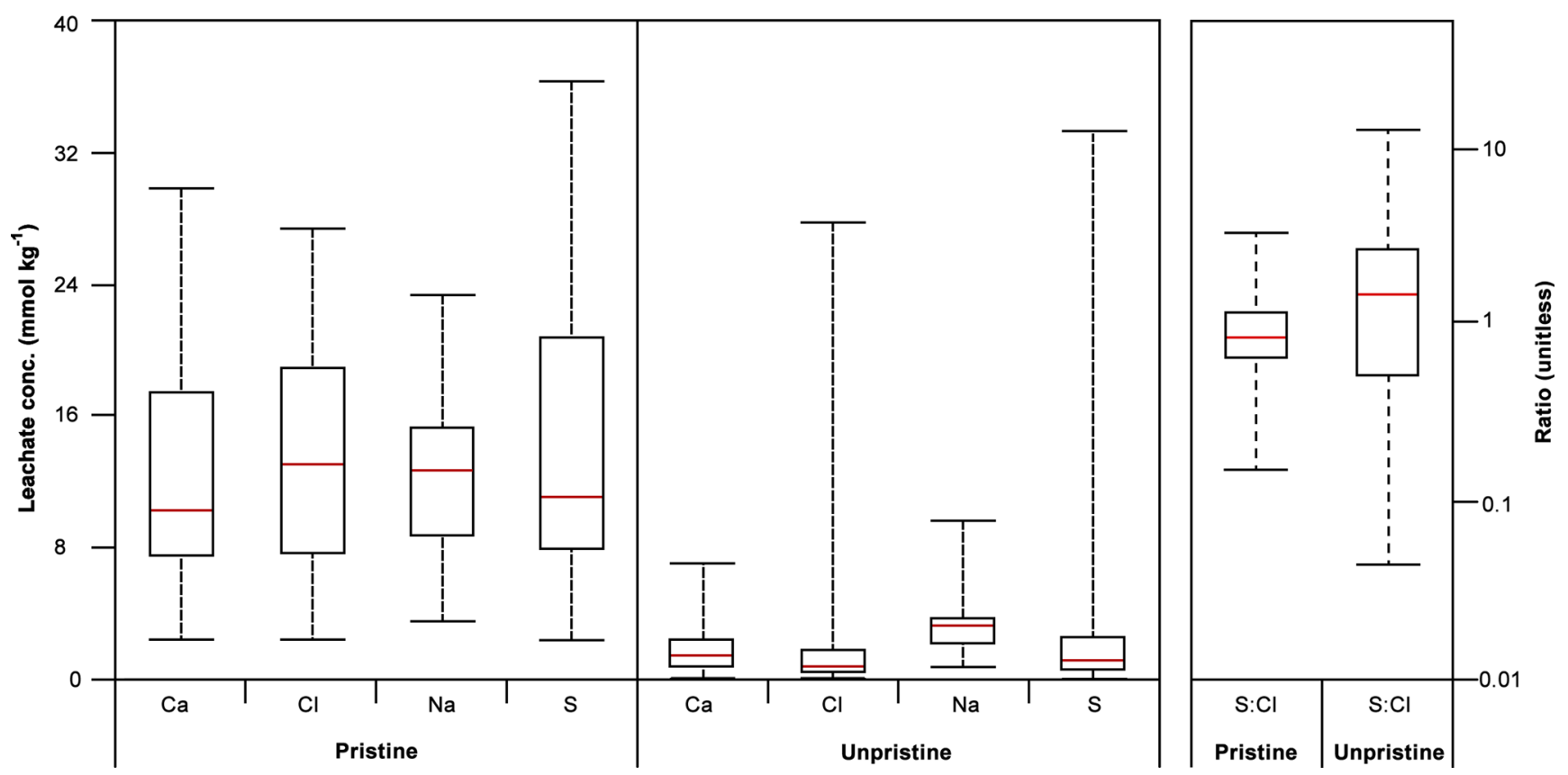

Fig. 12 Boxplot comparison of soluble $\mathrm{Ca}, \mathrm{Cl}, \mathrm{Na}$ and $\mathrm{S}$ concentrations, expressed in millimoles per kilogram to permit plotting on the same scale, and S/Cl ratios, from all pristine and unpristine tephra reported in Hinkley et al. (1987) and Nehring and Johnston (1981)

reported that tephra recovered from the Ritzville area, which received $45 \mathrm{~mm}$ of rain between May 18 and June 18, had lost in excess of $75 \%$ of soluble $\mathrm{S}$ and $\mathrm{Cl}$. We additionally compared the concentrations of soluble $\mathrm{Ca}, \mathrm{Cl}, \mathrm{Na}$ and $\mathrm{S}$ and the $\mathrm{S} / \mathrm{Cl}$ ratios, of all 49 unpristine samples to the pristine dataset (Fig. 12). For all elements in unpristine tephra, all concentrations below the 75th percentile of their respective datasets are lower than even the lowest concentrations in the pristine dataset. Furthermore, the $\mathrm{S} / \mathrm{Cl}$ ratios of unpristine samples are dissimilar to those of pristine tephra, perhaps reflecting the dissolution of S- and Cl-bearing compounds at different rates or in response to varying quantities of rainfall. Neither of these observations can be attributed to the spatial distribution of tephra samples, as the majority are recovered from areas either previously sampled, or in proximity to those areas. Thus, we emphasise that for any quantitative analysis of leachate compositions, the collection of pristine samples is of absolute importance, and echo the recommendations of the 2013 IVHHN guidelines in that researchers must 'try to collect tephra in a pristine (dry, not rained on) condition'.

\section{Conclusion}

We investigated the spatial structure of tephra leachate compositions from the MSH eruption, contrasting it with those of tephra deposit granulometry and chemical composition. We noted elevated leachate $\mathrm{Ca}, \mathrm{Cl}, \mathrm{Na}$ and $\mathrm{S}$ concentrations in blast zone deposits and a region of low $\mathrm{S} / \mathrm{Cl}$ and $\mathrm{Na} / \mathrm{Cl}$ ratios bounded by Ritzville and Spokane (WA) and Moscow and St. Maries (ID). Proximal enrichments may be the result of prolonged pre-eruptive exposure to magmatic gases during cryptodome growth. Conversely, the low $\mathrm{S} / \mathrm{Cl}$ and $\mathrm{Na} / \mathrm{Cl}$ ratios in the RSSM region may be due to the variable reactivity of ash to $\mathrm{SO}_{2}$ within the high-temperature eruption plume, and subsequent scavenging of $\mathrm{HCl}$ by ice- or water-coated ash, manifested in terrestrial deposits via both changes in magma composition and the influence of tephra dispersal and sedimentation patterns. However, analysis and mechanistic interpretation of these spatial features remains limited by the availability of samples, as well as insufficient characterisation and reporting of deposit stratigraphy and the physico-chemical properties of the tephra; thus, the spatial and temporal variability of leachate data remains poorly represented in both local areas and across the entire deposit. The influence of such limitations on our analysis emphasises the need for caution in any quantitative interrogation of leachate datasets. Additionally, future studies wishing to investigate gas-tephra interaction mechanisms, eruption dynamics or magmatic gas fluxes via leachate analysis should additionally construct and conduct their tephra sampling campaigns specifically to avoid those same limitations. Ultimately, to derive detailed mechanistic insights from leachate compositions may require sampling and characterisation of tephra deposits on an equal or greater scale than that associated with MSH. However, such an undertaking may only be possible in the event of a similar eruption, where extensive and accessible tephra deposits are emplaced within a highly populated continental landmass. 
Acknowledgments PA, DD and DBD were funded by AXA Research Grant 'Risk from volcanic tephra in the Earth system', and acknowledge the support of ERC Advanced Investigator Grant No. 247076 (EVOKES). PD and EM were supported by an FNRS (MIS-Ulysse Grant 326.F.6001.11) grant. BP wishes to acknowledge the helpful advice of Prof. Philippe Sonnet at Université Catholique de Louvain. PA is grateful to Dr. Carol Stewart and Prof. Kathy Cashman for their helpful comments on a pre-submission version of this paper. This paper has benefitted from the careful review and constructive comments of Dr. Michelle Coombs and Dr. Heather Wright. PA and AJD also acknowledge the generous donations of tephra from Andy Buddington, Steve Self, Elizabeth Zbinden, Andrei Sarna-Wojcicki and Elmira Wan at the USGS Tephrochronology Project. We further wish to thank all those who endeavoured to locate tephra, albeit unsuccessfully, on our behalf. We thank the USGS Cascades Volcano Observatory for providing the 2004 dome rock sample and Rick Hoblitt, Claire Horwell and Ed Llewellin for the support in collecting the 1980 cryptodome sample. We also thank the GJ Russell Microscopy Facility at Durham University for SEM support.

Open Access This article is distributed under the terms of the Creative Commons Attribution 4.0 International License (http:// creativecommons.org/licenses/by/4.0/), which permits unrestricted use, distribution, and reproduction in any medium, provided you give appropriate credit to the original author(s) and the source, provide a link to the Creative Commons license, and indicate if changes were made.

\section{References}

Armienta M, De la Cruz-Reyna S, Morton O, Cruz O, Ceniceros N (2002) Chemical variations of tephra-fall deposit leachates for three eruptions from Popocatepetl volcano. J Volcanol Geotherm Res 113(1):61-80

Ayris P, Lee A, Wilson K, Kueppers U, Dingwell D, Delmelle P (2013) $\mathrm{SO}_{2}$ sequestration in large volcanic eruptions: hightemperature scavenging by tephra. Geochim Cosmochim Acta 110:58-69

Ayris PM, Delmelle P, Cimarelli C, Maters EC, Suzuki YJ, Dingwell DB (2014) $\mathrm{HCl}$ uptake by volcanic ash in the high temperature eruption plume: mechanistic insights. Geochim Cosmochim Acta. doi:10. 1016/j.gca.2014.1008.1028

Bagnato E, Aiuppa A, Bertagnini A, Bonadonna C, Cioni R, Pistolesi M, Pedone M, Hoskuldsson A (2013) Scavenging of sulphur, halogens and trace metals by volcanic ash: the 2010 Eyjafjallajökull eruption. Geochim Cosmochim Acta 103:138-160

Barton AF (1991) CRC handbook of solubility parameters and other cohesion parameters. CRC, Boca Raton

Bonadonna C, Phillips JC (2003) Sedimentation from strong volcanic plumes. J Geophys Res Solid Earth (1978-2012) 108(B7)

Brunauer S, Emmett PH, Teller E (1938) Adsorption of gases in multimolecular layers. J Am Chem Soc 60(2):309-319

Carey SN, Sigurdsson H (1982) Influence of particle aggregation on deposition of distal tephra from the May 18, 1980, eruption of Mount St. Helens volcano. J Geophys Res Solid Earth (19782012) 87(B8):7061-7072

Carey S, Sigurdsson H, Gardner JE, Criswell W (1990) Variations in column height and magma discharge during the May 18, 1980 eruption of Mount St. Helens. J Volcanol Geotherm Res 43(1):99-112

Cashman KV (1992) Groundmass crystallization of Mount St. Helens dacite, 1980-1986: a tool for interpreting shallow magmatic processes. Contrib Mineral Petrol 109(4):431-449

Criswell CW (1987) Chronology and pyroclastic stratigraphy of the May 18, 1980, eruption of Mount St. Helens,
Washington. J Geophys Res Solid Earth (1978-2012) 92(B10):10237-10266

Delmelle P, Lambert M, Dufrêne Y, Gerin P, Óskarsson N (2007) Gas/ aerosol-ash interaction in volcanic plumes: new insights from surface analyses of fine ash particles. Earth Planet Sci Lett 259(1):159-170

Durant AJ, Rose W, Sarna-Wojcicki A, Carey S, Volentik A (2009) Hydrometeor-enhanced tephra sedimentation: constraints from the 18 May 1980 eruption of Mount St. Helens. J Geophys Res Solid Earth (1978-2012) 114(B3)

Durant AJ, Villarosa G, Rose WI, Delmelle P, Prata AJ, Viramonte JG (2012) Long-range volcanic ash transport and fallout during the 2008 eruption of Chaitén Volcano, Chile. Phys Chem Earth A B C 45:50-64

Ersoy O, Șen E, Aydar E, Tatar İ, Çelik HH (2010) Surface area and volume measurements of volcanic ash particles using micro-computed tomography (micro-CT): a comparison with scanning electron microscope (SEM) stereoscopic imaging and geometric considerations. J Volcanol Geotherm Res 196(3):281-286

ESRI (2012) ArcGIS desktop: release 10.1. Environmental Systems Research Institute, Redlands

Fruchter JS, Robertson DE, Evans JC, Olsen KB, Lepel EA, Laul JC, Abel KH, Sanders RW, Jackson PO, Wogman NS (1980) Mount St. Helens ash from the 18 May 1980 eruption: chemical, physical, mineralogical, and biological properties. Science 209(4461): $1116-1125$

Henley RW, King PL, Wykes JL, Renggli CJ, Brink FJ, Clark DA, Troitzsch U (2015) Porphyry copper deposit formation by subvolcanic sulphur dioxide flux and chemisorption. Nat Geosci 8(3): $210-215$

Herzog M, Graf H-F, Textor C, Oberhuber JM (1998) The effect of phase changes of water on the development of volcanic plumes. J Volcanol Geotherm Res 87(1):55-74

Hinkley T, Smith K, Taggart J Jr, Brown J, Wilson S, Gent C (1987) Chemistry of ash and leachates from the May 18, 1980 eruption of Mount St. Helens, Washington. USGS, Washington, p 73

Hoblitt R, Miller C, Vallance J (1981) Origin and stratigraphy of the deposit produced by the May 18 directed blast. In: PW L (ed) The 1980 eruptions of Mount St. Helens, Washington. USGS, Washington, pp 401-419

Hoshyaripour G, Hort M, Langmann B (2012) How does the hot core of a volcanic plume control the sulfur speciation in volcanic emission? Geochem Geophys Geosyst 13(7)

Hoshyaripour G, Hort M, Langmann B, Delmelle P (2014) Volcanic controls on ash iron solubility: new insights from high-temperature gas-ash interaction modeling. J Volcanol Geotherm Res 286:67-77

Jones MT, Gislason SR (2008) Rapid releases of metal salts and nutrients following the deposition of volcanic ash into aqueous environments. Geochim Cosmochim Acta 72(15):3661-3680

Mastin LG (2007) A user-friendly one-dimensional model for wet volcanic plumes. Geochem Geophys Geosyst 8(3)

McKnight DM, Feder GL, Stiles EA (1981) Toxicity of volcanic-ash leachate to a blue-green alga. Results of a preliminary bioassay experiment. Environ Sci Technol 15(3):362-364

Nehring NL, Johnston DA (1981) Use of ash leachates to monitor gas emissions. In: Lipman P (ed) The 1980 eruptions of Mount St. Helens, Washington. USGS, Washington, pp 251-254

Nič M, Jirát J, Košata B, Jenkins A, McNaught A (2009) IUPAC compendium of chemical terminology: gold book. IUPAC, Research Triangle Park, 2(0)

Óskarsson N (1980) The interaction between volcanic gases and tephra: fluorine adhering to tephra of the 1970 Hekla eruption. J Volcanol Geotherm Res 8(2):251-266 
Pallister JS, Hoblitt RP, Crandell DR, Mullineaux DR (1992) Mount St. Helens a decade after the 1980 eruptions: magmatic models, chemical cycles, and a revised hazards assessment. Bull Volcanol 54(2): 126-146

Rumstidt JD (2013) Geochemical rate models: an introduction to geochemical kinetics. Cambridge University Press, Cambridge, 239 pp

Rose W, Bonis S, Stoiber R, Keller M, Bickford T (1973) Studies of volcanic ash from two recent Central American eruptions. Bull Volcanol 37(3):338-364

Rose WI (1977) Scavenging of volcanic aerosol by ash: atmospheric and volcanologic implications. Geology 5(10):621-624

Sarna-Wojcicki A, Meyer C, Woodward M, Lamothe P (1981a) Areal distribution, thickness, mass, volume, and grain size of air-fall ash from the six major eruptions of 1980. In: Lipman P (ed) The 1980 eruptions of Mount St. Helens, Washington. USGS, Washington, pp $577-600$

Sarna-Wojcicki A, Meyer C, Woodward M, Lamothe P (1981b) Composition of air-fall ash erupted on May 18, May 25, June 12, July 22, and August 7. In: Lipman P (ed) The 1980 eruptions of Mount St. Helens, Washington. USGS, Washington, pp 667-682

Scheidegger KF, Federman AN, Tallman AM (1982) Compositional heterogeneity of tephras from the 1980 eruptions of Mount St. Helens. J Geophys Rese Solid Earth (1978-2012) 87(B13):10861-10881

Smith DB, Zielinski RA, Taylor HE, Sawyer M (1983) Leaching characteristics of ash from the May 18, 1980, eruption of Mount St. Helens volcano, Washington. Bull Volcanol 46(2):103-124

Sneva FA, Britton CM, Mayland HF, Buckhouse J, Evans RA, Young JA, Vavra M (1982) Mt. St. Helens ash: considerations of its fallout on rangelands. Agricultural Experiment Station and Extension Service Special Report No. 650, 27pp
Sorem RK (1982) Volcanic ash clusters: tephra rafts and scavengers. J Volcanol Geotherm Res 13(1):63-71

Stewart C, Horwell C, Plumlee G, Cronin S, Delmelle P, Baxter P, Calkins J, Damby D, Morman S, Oppenheimer C (2013) Protocol for analysis of volcanic ash samples for assessment of hazards from leachable elements. Retrieved from http://www.ivhhn.org/ guidelines.html. Accessed 10 June 2015

Stoiber RE, Williams SN, Malinconico LL Jr, Johnston DA, Casadevall TJ (1981) Mt. St. Helens: evidence of increased magmatic gas component. J Volcanol Geotherm Res 11(2):203-212

Sung FC, Nevissi AE, Dewalle FB (1982) Water-soluble constituents of Mount St. Helens ash. J Environ Sci Health A 17(1):45-55

Taylor PS, Stoiber RE (1973) Soluble material on ash from active Central American volcanoes. Geol Soc Am Bull 84(3):1031-1042

Taylor HE, Lichte FE (1980) Chemical composition of Mount St. Helens volcanic ash. Geophys Res Lett 7(11):949-952

Textor C, Graf HF, Herzog M, Oberhuber J (2003) Injection of gases into the stratosphere by explosive volcanic eruptions. J Geophys Res Atmos (1984-2012) 108(D19)

Varekamp JC, Luhr JF, Prestegaard KL (1984) The 1982 eruptions of El Chichón Volcano (Chiapas, Mexico): character of the eruptions, ashfall deposits, and gas phase. J Volcanol Geotherm Res 23(1):39-68

Waitt RB, Dzurisin D (1981) Proximal air-fall deposits from the May 18 eruption - stratigraphy and field sedimentology. In: Lipman P (ed) The 1980 eruptions of Mount St. Helens, Washington. USGS, Washington, pp 601-616

Witham CS, Oppenheimer C, Horwell CJ (2005) Volcanic ash-leachates: a review and recommendations for sampling methods. J Volcanol Geotherm Res 141(3):299-326 